\title{
AN EXPERIMENTAL ANALYSIS OF THE RELATION BETWEEN PHYSIOLOGICAL STATES AND RHEOTAXIS IN ISOPODA
}

\author{
W. C. ALLEE \\ From the Zoölogical Laboratory, University of Chicago \\ TEN FIGURES \\ CONTENTS
}

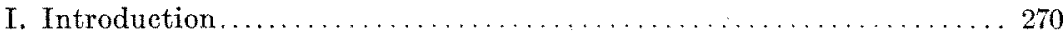

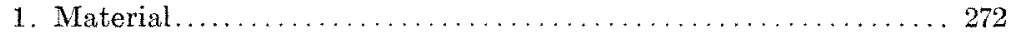

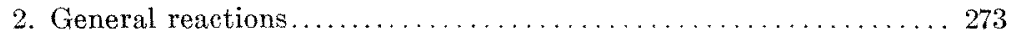

3. Methods . . . . . . . . . . . . . . . . . . . . . . . . . . . . 275

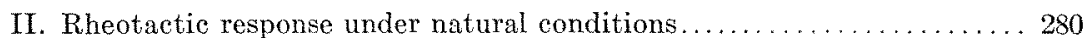

1. Stream Aselli. . . . . . . . . . . . . . . . . . . . . . . . . . . 280

a. Normal adults.................................. 280

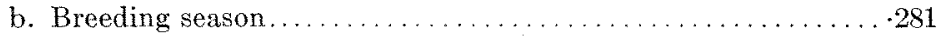

c. Juvenile mores. . . . . . . . . . . . . . . . . . . . . . . . . . 285

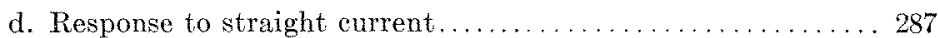

2. Pond Aselli..................................... 289

a. Adults.............. . . . . . . . . . . . . . . . . . 289

b. Juvenile pond isopods... . . . . . . . . . . . . . . . . . 292

c. Response to straight current..................... 293

3. Summary of rheotactic response given under natural environmental

conditions. . . . . . . . . . . . . . . . . . . . . . . . 294

III. Rheotactic response under experimental conditions . . . . . . . . . . . 296

1. Stream Aselli. . . . . . . . . . . . . . . . . . . . . . . . 296

a. With decreased oxygen ........................ 296

(1) Normal adults..... . . . . . . . . . . . . . . . . . . 297

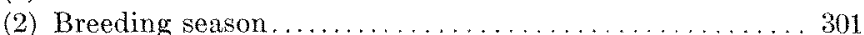

(3) Juvenile stream Aselli . . . . . . . . . . . . . . . . . . . 304

(4) Response to straight current ................... 308

b. Carbon dioxide .................. . . . . . . . . . 300

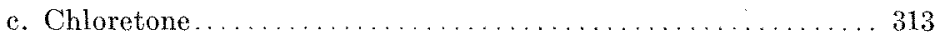

d. Potassium cyanide $\ldots \ldots \ldots \ldots \ldots \ldots \ldots \ldots \ldots \ldots \ldots \ldots \ldots$

e. Low temperature . . . . . . . . . . . . . . . . . . . . . . . 316

f. Starvation.................................. 317 


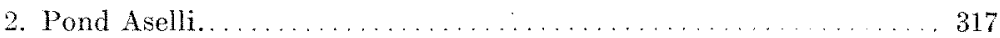

a. With increased oxygen.......................... 317

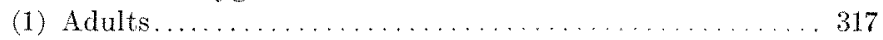

(2) Juvenile mores. .......................... 321

(3) Response to straight current............... 321

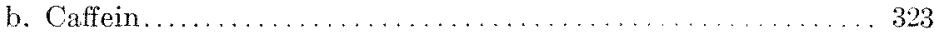

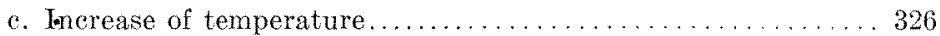

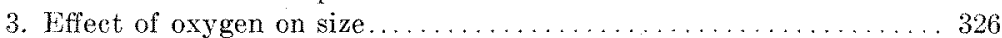

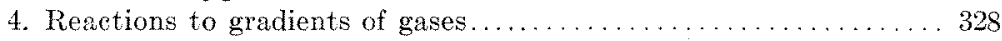

5. Summary of experimental results . . . . . . . . . . . . . . . 332

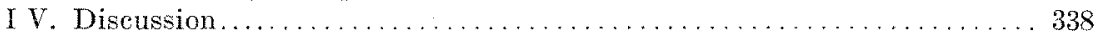

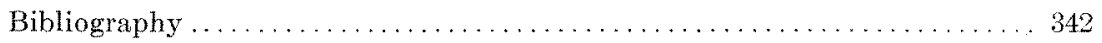

\section{INTRODUCTION}

This paper is the result of an investigation into the rôle played by the 'physiological state' of the organism in determining its reactions. Jennings ('06, pp. 286-292) summed up the work along this line, by Moebius ('73), Romanes ('85), Preyer ('86), Uexküll ('97, '99, '00,) Yerkes ('02), Smith ('02), Pearl('03), Mast ('03), Bohn ('03, '03 a, '05), Gamble and Keeble ('03), Yerkes and Huggins ('03), Jennings ('04 b, '04d), Spaulding ('04), Holmes ('05) and Harper ('05). From this work he drew the following conclusions: (1) Changes in activity depend on changes in physiological states. (2) Reactions to external conditions depend on physiological states. (3) The physiological state may be changed by (a) progressive internal processes, (b) by the action of external agents, (c) by the activity of the organism. External agents cause reactions by changing the physiological state of the organism. (5) The behavior of the organism at any moment deperds on its physiological state at that moment. (6) Physiological states change either according to the laws affecting metabolism or according to those controlling stimulation.

These statements, however, were supported by little direct experimental evidence and Jennings recognized this, for he says (06, p. 251):

The diverse physiological states of lower organisms have been little studied. This is partly because it is rarely possible to observe them directly; it is only through their effects upon action that they become evident. Thus the real data of observations are the actions; if we con- 
sider these alone, we could only state that a given organism reacts under the same external conditions sometimes in one way, sometimes in another. This would give us nothing on which to base a formulation and analysis of behavior, so that we are compelled to assume the existence of changing internal states. This assumption besides being logically necessary, is of course, supported by much positive evidence drawn from diverse fields, and there is reason to believe that in time we shall be able to study these states directly. ${ }^{1}$ Before we can come to a full understanding of behavior, we shall have to subject the physiological states of organisms to a detailed study and analysis, as to their objective nature, causes and effects.

In commenting on Jennings' position, Mast ('11, pp. 375-378) placed some emphasis on another factor. He said in part:

It is evident, that while there is some evidence bearing on physiological states we know but little about their nature and regulation. For all that is known to the contrary, subjective factors, entelechies, or psychoids, factors foreign to inorganies, may have a hand in controlling physiological changes and consequently the reactions.

Whether or not there are any such phenomena is the question at issue. But until this question is settled . . . . those who maintain . . . . there are no entelechies are certainly nu more scientific than those who maintain the opposite.

The analysis of the relationship existing between the physiological state of the isopods used and their rheotactic reaction has been carried on in accordance with the statements of Jennings just quoted. The work has proceeded far enough at present to enable one to predict with certainty the action that will result from a physiological state experimentally produced, so that in this case the behavior of the animals becomes a check on the production of a physiological state as well as an indicator that a change must have occurred. While it is as yet impossible to control with certainty all the minor details of the reaction, yet sufficiently complete control has been maintained to show that in the rheotactic response with these animals there is no necessity to call in any 'factor foreign to inorganics' in order to explain the changes in physiological states.

1 Italics mine. 


\section{MATERIAL}

The isopods used in this study have almost all been Asellus communis Say. In a very few cases trials have been made with Mancasellus danielsii Rich. Asellus communis is the common fresh water isopod. Richardson ('05, p. 420) gives its distribution as extending from Massachusetts and Connecticut on the east to Illinois and Louisiana on the west. Near Chicago it is found throughout the year in the older ponds of the series at the south end of Lake Michigan (Allee, '11, p. 126; Shelford '11 a, maps) and in young streams, particularly those which have permanent pools and temporary riffles. Most of the stream isopods used in the course of this work were taken from the County Line Creek near Glencoe, Illinois (Shelford '11, maps pp. 14; 17). In general their stream distribution parallels that of the horned dace, Semotilus atromaculatus (Shelford '11, p. 17). In the spring these isopods are very abundant in the small temporary ponds especially where there is a thick covering of leaves over the bottom which guards against too severe desiccation in the dry periods. The Mancasellus danielsii have never been taken from a stream or from the small summer-dry ponds in this vicinity. They are limited mainly to the series of ponds mentioned above, although some have been taken from a spring fed, watercress marsh at Cary, Illinois. In the Chicago area they have never been found in a place not containing $\mathrm{A}$. communis.

In early spring the isopods are usually found along the margins of the ponds, later in the season they are more common in deeper water (Allee, '11). They crawl around over the vegetation and bottom and are almost never seen swimming. There is a distinct daily movement that is more pronounced in the deeper water. Here they are more numerous at the surface during times of dim light and retire to the bottom when exposed to bright sunlight. If the pond dries, they burrow into the mud and are thus able to withstand droughts extending over several moutius. In the streams, they are usually found in protected positions, often hiding among a bunch of leaves or other débris. In streams with rocky beds they may occur under stones. 
Much material collected from all places isopods are known to inhabit in this region, was identified by Miss Richardson in 1910 as consisting entirely of the two species mentioned. The appearance of the two is entirely different, so that there is no chance of any of the results obtained being due to a mixing of species. Regarding A. communis, Miss Richardson says, in a private communication:

Asellus communis is a very variable species. The uropods in some specimens differ considerably from the typical form, in being shorter and of varying lengths, while in other specimens they are narrower. I think these differences may be due to size, age, and in some cases the parts may be in process of regeneration. Then too the propodus of the first pair of legs in the male differs in the specimens, being larger in some than in others and with spines more pronounced. There are so many intermediate stages that it was not possible to group the specimens into varieties as I had at first supposed could be done.

A careful study of a large number of specimens from both ponds and streams showed these variations to be equally common in all habitats. Thus the differences found in the reactions cannot be due to taxonomically differing races.

\section{GENERAL REACTIONS}

The experimental work upon which this paper is based was begun in the summer of 1909 and has been in progress continuously since that time. The early experiments upon the general responses run parallel with those of Banta ('10). A summary of these general reactions of $\mathrm{A}$. communis will be given, in order that the conditions of the later experiments may be better appreciated. Unless otherwise indicated, the results are my own and in almost every instance they support the results obtained by Banta.

1. The main breeding period in these isopods extends from the middle of March to the middle of July but this may be extended in scattered cases until the beginning of cold weather. During the copulation the males carry the females for as many as three days. The developmental period is about three weeks and on the average forty offspring are liberated each time. The number of offspring may be much larger, and in one instance two hun- 
dred young were taken from a single brood pouch. More than one brood is brought forth by the same female in one season. Some of the animals may live over another winter although many of them die off at the close of the breeding season. In nature the breeding habitat is restricted to the most favorable locations. Banta did no work with animals during the breeding season.

2. The food of A. communis as determined both by observing their feeding habits and by examining their alimentary tract, consists of algae, larger green water plants, protozoa, decaying leaves and dead animals.

3. They are strongly positive to gravity and water pressure when these are acting alone but if light is introduced the reaction is controlled by the light.

4. A. communis is strongly positive to tactile stimuli. The hairs are sensitive to touch so that a response is given, even when antennae, antennules, and uropods are removed. The positive thigmotaxis is shown by their tendency to collect in corners or under thin mica plates. Again if subjected to the action of light they will disregard their thigmotactic optimum and respond to light alone.

5. Their temperature optimum varies, depending on the temperature in which they have been kept. Sudden temperature changes in either direction cause them to collect in bunches, more extreme changes cause the 'pill bug' reaction and if these conditions continue death results.

6. A. communis is negative to direct sunlight or to a large amount of diffuse light although they are positive to room light admitted through a very small opening. Young animals are negative to all light intensities used. The adults have a light optimum, as this shifts they change their position until they are in optimum conditions. The response to light is affected by their previous exposure. Banta ('10, pp. 263-269) found in this connection that after being in darkness for several hours Asellus is positive to all light intensities tried, the duration of the positive response depending on the intensity of the light. In my experiments however they were most positive to faint light after forty hours continuous exposure to a light intensity of 80 candle 
meters. If exposed to the colors of the spectrum they collect in the red end and animals exposed to red light act almost as if in complete darkness. Aselli are nocturnal in their habits and in ponds or aquaria there is a diurnal movement, depending, in part at least, on light conditions.

7. Banta (1. c., pp. 440-467) found that they were sensitive to mechanical stimulation with bristles; with localized currents of water; with concussion; and with vibrations at the rate of 100 per second. The results with localized currents of water showed the most sensitive parts of Asellus to be on the head and at the base of the antennae, and these responses were only gained with the strongest currents used.

\section{METHODS}

At the beginning of the work on rheotaxis it was necessary to devise some method that would permit rapid testing of a large number of animals and in which the personal equation should be reduced to a minimum. Also the method used must be applicable to both field and laboratory work. For this reason it was thought best to use a circular current, although Allen ('10) in an unpublished master's thesis showed that the current set up in a circular pan is not straight but forms a diverging spiral.

The method used is as follows: The isopods were placed in an enamel-ware pan $25 \mathrm{~cm}$. in diameter and $6 \mathrm{~cm}$. deep. In order that they might have a firm foot hold for crawling the pan bottom was covered with a layer of bees-wax. The animals were placed in $2 \mathrm{~cm}$. of the same water in which they had been kept. In the laboratory the pan was then set in a dark box under an illumination of one candle meter. One side of this box was curtained so that later the tests could be made withoutintroducing outside light. Usually five isopods were used although this number was varied with the size and condition of the animals. The animals were undisturbed for fifteen minutes in order to allow them to become accustomed to the new conditions and to permit a recovery from the shock of handling. In case they had been kept at a temperature differing from that of the room the pan was 
placed in a bath that would keep the temperature within one degree of that to which they were accustomed. In the field the trials were made in diffuse light, with all other conditions as near those of the laboratory trials as was possible.

After fifteen minutes a current was produced by stirring with a glass rod about $8 \mathrm{~mm}$. in diameter. In order to secure as even a current as possible the rod was run five times around the pan at a distance of about $4 \mathrm{~cm}$. from the edge and at a uniform rate. The attempt was made to keep from stirring the animals from the bottom. Usually they remained along the edge of the pan and thus were in that part of the current that shows the least spiral tendency. Time was taken with a stop watch for one minute after the stirring stopped and the reaction of each animal for the greater part of the minute was recorded. Thus if an animal went against the current for forty seconds and with it for the remainder of the minute it was counted positive, while if it went with the current half the time and against it the other half it was counted indifferent. At the end of the minute reaction, the current was set up in the reverse direction. The reason for reversing the direction of the current, is that isopods tend to continue in the same direction in which they are started. Thus if by accident negative isopods are all going against the current and at the end of the minute's reaction the current is merely renewed, there would be a tendency to remain positive although in reality their normal reaction would be negative or indifferent. If on the other hand the current is reversed, then if they are strongly positive they will reverse their direction thereby showing that they are reacting to the direction of the current and not to chance factors.

Trials were continued in this fashion until ten consecutive tests had been made. These results were recorded and the percentage of animals going positively, negatively, and indifferently was calculated. It is to be regretted that there is as much left to the personal equation as there is in this method, yet it furnishes a fairly stereotyped set of trials that have given closely comparable results. The positive reaction obtained under these conditions, consists of two factors, namely: (1) The percentage of positive responses numerically stated and (2) the positiveness with which 
the response may be given, that is, the speed and definiteness of the response. Experiments have shown that these two qualities of the response are closely correlated and when either is stated in this discussion, the other is always implied.

The possibilities of this method are shown in table 1 . The Aselli used in this experiment were carefully selected from a stock of stream isopods that had been reared in known conditions in the laboratory. They were about five months old and were between 9 and $10 \mathrm{~mm}$. in length. All were in the same stage

TABLE 1

Table showing possibilities of the method used. Eight stream Aselli, 8 to $9 \mathrm{~mm}$. long; twenty-four hour intervals

\begin{tabular}{|c|c|c|c|c|c|}
\hline $\mathrm{O}_{2}$ & \multicolumn{3}{|c|}{ RESPONSE* } & $\begin{array}{l}\text { NUMBER oF } \\
\text { TRIALS }\end{array}$ & $\frac{\text { TEMPERATURE }}{\mathrm{C}}$ \\
\hline ce. per liter & per cent + & per eent - & per cent $\propto$ & & \\
\hline 6.49 & 90 & 10 & 0 & 80 & 18 \\
\hline 6.49 & 89 & 11 & 0 & 80 & 18 \\
\hline 7.11 & 89 & 10 & 1 & 80 & 18 \\
\hline 6.90 & 91 & 9 & 0 & 80 & 18 \\
\hline 6.90 & 85 & 11 & 4 & 80 & 18 \\
\hline$\gamma .00$ & 91 & 9 & 0 & 80 & 18 \\
\hline 7.40 & 90 & 8 & 2 & 80 & 15 \\
\hline
\end{tabular}

Average positive response 89.4 per cent.

Greatest deviation from average 4.9 per cent.

* + indicates a positive reaction.

- indicates a negative reaction.

$\propto$ indicates an indifferent reaction.

regarding moulting, and were entirely normal in every way. Throughout their life they had been kept in still water having an average of about $6 \mathrm{cc}$. of oxygen per liter.

From table 1 it will be seen that with animals in approximately the same physiological state, the experimental error of the method used is almost 5 per cent. This error is too large for purely quantitative results, but it will not interfere greatly with the comparisons that are to be made in this work. In no case however is any importance attached to experimental results that do not show a difference of at least 20 per cent, so that the possible error of 5 per cent cannot affect the conclusions drawn. 
The results of another check on the constancy of the rheotactic response to a circular current are given in figure 1, which shows graphs of twenty-five successive responses of one male Asellus. The animal used was a stream isopod $11 \mathrm{~mm}$. long, that had been
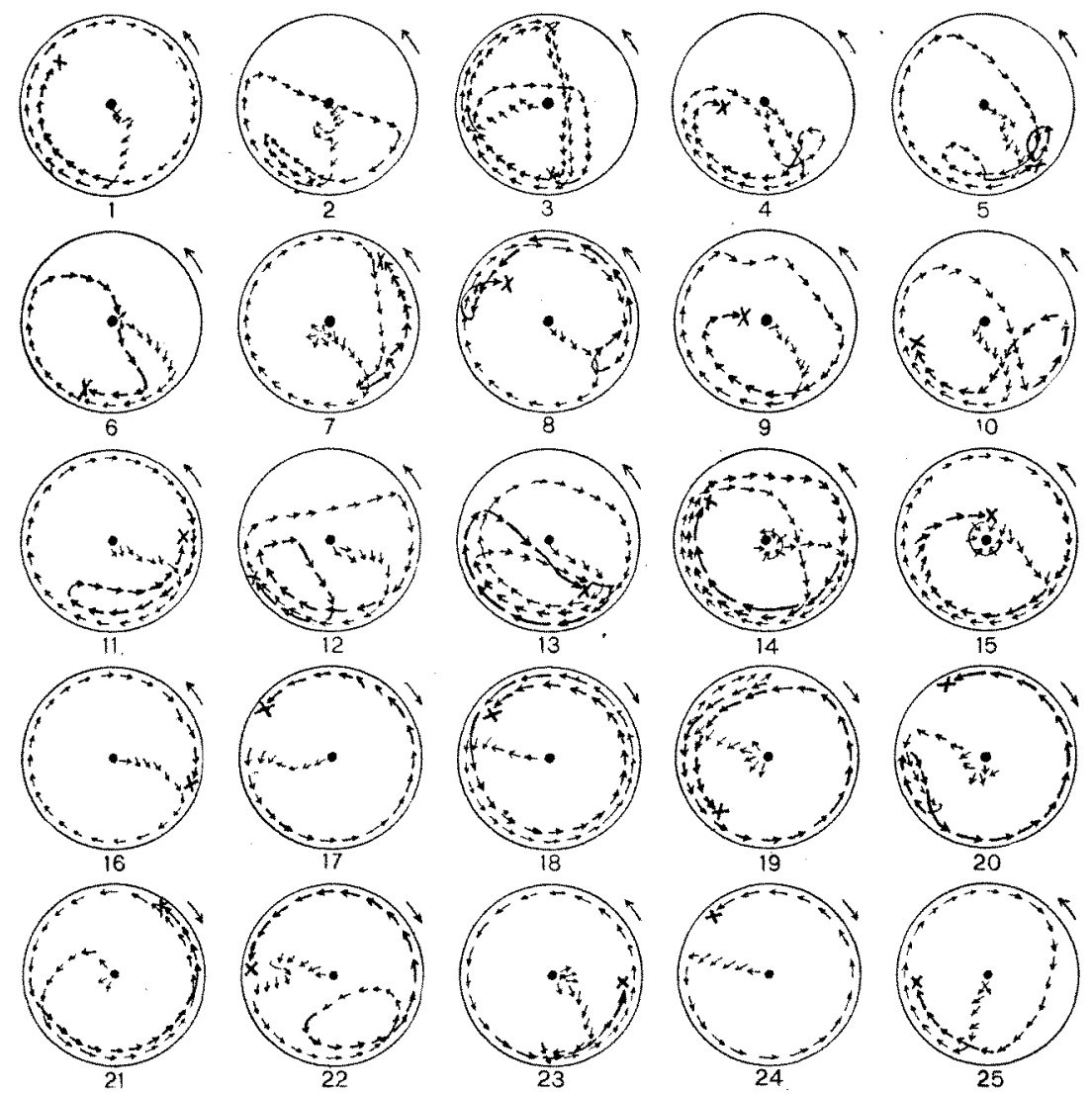

Fig. 1 Twenty-five successive rheotactic reactions of one stream Asellus

kept in water with the oxygen at air saturation. In this case the trials were made in a glass dish $10 \mathrm{~cm}$. in diameter. The current used was strong enough to sweep the isopod to the center each time and the presence of the spiral current is plainly shown by the path taken in reaching the circumference of the dish. 
In the figure the starting point is indicated by a large dot; the end point, by a cross. The arrow on the outside of the circle indicates the direction of the current.

In all cases, excepting no. 23 , the animal responded positively to the current, that is, it gave a 96 per cent positive response. Evidently its normal reaction was a positive one and the one failure to go against the current would then mean a chance turning that was not corrected. That is, in this case there is an experimental error of 4 per cent, which checks well with that shown in table 1. These results also show that the isopods will give their normal response for at least twenty-five successive trials, so that it is entirely safe to take the first ten responses as indicating the normal behavior of the animals tested.

During these experiments the oxygen content of the water has been determined by the Winkler method. During the first part of the work, the method was followed as outlined in the report of the committee on standard methods of water analysis to the laboratory section of the American Health Association ('05, pp. 74-77). The free carbon dioxide was determined by direct titration with $\mathrm{N} / 22$ sodium carbonate using phenolphthalein as an indicator. This method is described in the same report (pp. 72-73). After the appearance of Birge and Juday's work ('11, pp. 13-24), their methods were followed wherever the technique appeared better. Birge and Juday compared this method of determining the oxygen content of the water with that of boiling and found (1. c., pp. 11-12) that the amount of variation in results from the two methods was not more than was the case in duplicate determinations by the same method. V. E. Shelford and the writer verified these results and the methods used have proved eminently satisfactory for rapid biological work. 
II. RHEOTACTIC RESPONSE UNDER NATURAL CONDITIONS

\section{STREAM ASELLI \\ a. Normal adults}

Table 1 and figure 1 show responses of stream isopods at their highest rate of positiveness. Usually under the conditions used the per cent of positive response was somewhat lower. A list of the results of these tests is given in table 2 . It will be seen that the results of different trials vary somewhat, the greatest varia-

TABLE 2

Normal rheotactic response of adult stream Aselli

\begin{tabular}{|c|c|c|c|c|c|}
\hline $\mathrm{O}_{2}$ & & RESPONSE & & NUMBER OF & TEMPERATURE \\
\hline$c c$. per liter & percent + & percent - & per cent $\propto$ & & \\
\hline 5.12 & 72 & 20 & 8 & 60 & 17 \\
\hline 5.46 & 78 & 12 & 10 & 50 & 17 \\
\hline 5.5 & 70 & 12 & 18 & 50 & 18 \\
\hline 5.69 & 78 & 12 & 10 & 50 & 18 \\
\hline 5.92 & 70 & 24 & 6 & 80 & 18 \\
\hline 5.97 & 70 & 18 & 12 & 60 & 17 \\
\hline 6.03 & 80 & 20 & 0 & 30 & 18 \\
\hline 6.03 & 88 & 6 & 6 & 60 & 18 \\
\hline 6.15 & 76 & 14 & 10 & 80 & 18 \\
\hline 6.26 & 80 & 14 & 6 & 50 & 20 \\
\hline 6.36 & 75 & 25 & 0 & 40 & 17 \\
\hline 6.49 & 89 & 8 & 3 & 60 & 18 \\
\hline 6.55 & 99 & 7 & 0 & 80 & 12 \\
\hline 6.57 & 72 & 18 & 10 & 50 & 19 \\
\hline 6.77 & 86 & 13 & 1 & 70 & 15 \\
\hline 7.00 & 88 & 6 & 6 & 50 & 23 \\
\hline 7.02 & 72 & 8 & 20 & 50 & 13 \\
\hline 7.51 & 89 & 17 & 1 & 80 & 10 \\
\hline 7.54 & 73 & 27 & 0 & 30 & 18 \\
\hline 8.14 & 79 & 21 & 0 & 80 & 18 \\
\hline 8.14 & 85 & 11 & 4 & 80 & 17 \\
\hline 8.14 & 83 & 12 & 5 & 80 & 17 \\
\hline 8.59 & 86 & 4 & 10 & 50 & 16 \\
\hline 9.22 & 84 & 4 & 12 & 50 & 6 \\
\hline 9.31 & 78 & 8 & 14 & 50 & 6 \\
\hline 9.34 & $7 / 4$ & 10 & 16 & 50 & 8 \\
\hline 10.25 & 78 & 18 & 4 & 50 & 11 \\
\hline 6.41 & 79 & 14 & 7 & 1570 & \\
\hline
\end{tabular}


tion being 18 per cent from the mean. These variations may be due to length of time since moulting or age. The group giving the highest positive response had been carefully selected to represent animals in the best possible condition. In all the other cases the animals were simply picked at random from the general stock. The variation' in oxygen content of the water within the limits given in table 2 does not appear to have any marked significance although in general the lowest positive responses are found with the lowest oxygen content. Apparently there is sufficient oxygen here for the usual activities to be carried on at the usual rate and not enough to stimulate them greatly. The length of time the animals have been in the laboratory does not affect their response providing they are kept in conditions resembling as nearly as possible, those in their usual habitat.

The response of these stream isopods to the current is vigorous and usually definite, that is, they are either definitely positive or negative. When the current is reversed they tend to reverse within the first ten seconds after the new current is set up, and often they are all reversed before the stirring is stopped. They also move vigorously, sometimes completing two circumferences of the pan in the minute reaction time allowed. This would mean a rate of about $80 \mathrm{~cm}$. per minute. They sometimes pivot on their posterior end, turning their head in a complete circle before starting a definite reaction and this testing reaction is usually followed by a positive response.

In all these cases the amount of free carbon dioxide in the water was very low. That is, it never exceeded 3 cc. per liter of water 'nd usually ran much lower, the average being about $2 \mathrm{cc}$. per ter. Thus the variations of the free carbon dioxide are too small to be of any significance, and the fact that it was present in such small amounts will have to be considered in determining the cause of the high percentage of positive reactions.

\section{b. Breeding season}

The breeding season of these isopods begins before the ice is out of the water in the spring. It reaches its culmination by the last of April and gradually diminishes. Occasionally breeding 
occurs throughout the summer but is very rare during August and September. As the weather becomes colder, a new period sets in, but this is of much shorter duration than the spring periods. The shortening cannot be wholly due to the increasing coldness because animals brought into the laboratory and kept under normal conditions do not long continue breeding. In these animals in the laboratory, however, a new period of breeding begins about the first of December. Starting with a few individuals it slowly increases in importance until by the middle of January, it is the dominant activity of the animals. Curiously enough this is much more pronounced in animals kept at temperatures about $5^{\circ} \mathrm{C}$. than in those at $20^{\circ}$. In these laboratory isopods the season stops about the time it is reaching its height in the field.

One sign of the approach of the breeding season is the increased tendency to collect in bunches. Bunching is apt to occur at any time during the year if conditions become unfavorable, as when there is a sudden drop in temperature, but the bunching tendency of the breeding season is even stronger. Often these close irregular groupings occur, containing six or eight individuals. This is especially apt to happen when the animals are stirred in a current so that they are thrown against each other. The copulation occurs much as Holmes has described for amphipods (Holmes '03, p. 288). The females may become quite helpless as the brood pouch develops and unless they are clinging to some support, they are often brought to the surface and float around ventral side up, entirely unable to right themselves or to regain the bottom unless they chance upon some solid object.

The effect of the breeding season on the rheotactic response of stream Aselli is shown in table 3. The first part of the table gives the cycle of reactions due to the breeding season as shown in the field experiments from April till October. The second part traces the progress of these influences upon laboratory stock during the winter months. One of the most noticeable changes in the rheotactic response is the marked decrease in the percentage of positive responses. Another almost as striking is the extreme variability in animals selected at random from the breeding stock. This variability is not so apparent when the same animals are 
TABLE 3

Part 1. Field trials. The effect of the breeding season on the rheotactic response of adult stream Aselli

\begin{tabular}{|c|c|c|c|c|c|c|c|}
\hline $\mathrm{O}_{2}$ & & RESPONSE & & $\begin{array}{l}\text { NUMBER } \\
\text { OF TRLALS }\end{array}$ & $\begin{array}{l}\text { TEMPER- } \\
\text { ATURE }\end{array}$ & DATE & REMARKS \\
\hline cc.perliter & percent + & per cent - & percent $\propto$ & & & & \\
\hline 9.31 & 38 & 14 & 48 & 50 & 13 & 46 & $3 \%$ b.p. $2 \sigma^{*}$ \\
\hline 7.80 & 9 & 74 & 17 & 80 & 9 & $4-22$ & $4 \circ 4 \sigma^{\pi}$ \\
\hline 7.55 & 48 & $4 \grave{s}$ & 7 & 60 & 9 & $4-22$ & all ? \\
\hline 7.55 & 33 & 60 & 7 & 40 & 10 & $4-22$ & all $q$ \\
\hline 7.55 & 40 & 42 & 18 & 50 & 10 & $4-22$ & all $\%$ \\
\hline 7.28 & 36 & 60 & 4 & 70 & 14 & $4-29$ & all with b.p \\
\hline 7.28 & 12 & 44 & 44 & 50 & 14 & $4-29$ & all $\sigma^{\gamma}$ small \\
\hline 7.28 & 50 & 32 & 18 & 50 & 14 & $4-29$ & all ơ large \\
\hline 7.28 & 32 & 58 & 10 & 50 & 14 & $5-16$ & mixed \\
\hline 7.28 & 48 & 52 & 0 & 50 & 14 & $5-16$ & mixed \\
\hline 1.02 & 14 & 80 & 6 & 50 & 18 & $5-21$ & mixed; no bp. \\
\hline 1.02 & 11 & 63 & 26 & 50 & 18 & $5-21$ & 5 prs. cop. \\
\hline 5.30 & 42 & 52 & 6 & 50 & 18 & $5-21$ & $4910^{7}$ \\
\hline 4.50 & 48 & 52 & 0 & 40 & 18 & $5-21$ & mixed \\
\hline 4.65 & 0 & 70 & 30 & 20 & 18 & $5-21$ & 2 prs. cop. \\
\hline 5.69 & 60 & 40 & 0 & 10 & 23 & $6-8$ & $q$ \\
\hline 5.69 & 68 & 24 & 8 & 50 & 23 & $6-8$ & mixed \\
\hline 5.01 & 5.3 & 42 & 5 & 45 & 16 & $6-17$ & $3 \% 2$ व $^{7}$ \\
\hline 6.26 & 14 & 82 & 4 & 50 & 23 & $7-8$ & mixed \\
\hline 7.00 & 88 & 6 & 6 & 50 & 23 & $8-1$ & normal \\
\hline 5.46 & 78 & 12 & 10 & 50 & 17 & $10-4$ & normal \\
\hline 8.54 & 50 & 46 & 4 & 50 & 13 & $10-5$ & $\begin{array}{l}\text { selected with } \\
\text { b.p. }\end{array}$ \\
\hline
\end{tabular}

* b.p. stands for females with brood pouches.

Part 2. Breeding season in laboratory stock

\begin{tabular}{|c|c|c|c|c|c|c|c|}
\hline 6.05 & 57 & 40 & 3 & 30 & 18 & $\begin{array}{r}12-4 \\
1912\end{array}$ & copulating \\
\hline 7.34 & 50 & 47 & 3 & 60 & 4 & $1-11$ & 1 pr. cop. \\
\hline 9.54 & 44 & 20 & 36 & 50 & 6 & $1-19$ & mixed \\
\hline 9.54 & 54 & 12 & 34 & 50 & 8 & $1-19$ & mixed \\
\hline 9.54 & 59 & 33 & 14 & 50 & 10 & $1-19$ & mixed \\
\hline 9.54 & 60 & 20 & 20 & 20 & 8 & $1-23$ & mixed \\
\hline 9.54 & 70 & 10 & 20 & 20 & 8 & $1-23$ & 2 prs. cop. \\
\hline 10.47 & 28 & 51 & 21 & 80 & 4 & $1-28$ & all large o \\
\hline 8.73 & 21 & 23 & 56 & 80 & 4 & $1-30$ & mixed \\
\hline 7.83 & 30 & 29 & 41 & 80 & 4 & $1-13$ & mixed \\
\hline 8.88 & 27 & 30 & 43 & 70 & 6 & $1-31$ & mixed \\
\hline 9.11 & 29 & 16 & 55 & 70 & 6 & $2-2$ & mixed \\
\hline 8.82 & 27 & 23 & 50 & 70 & 4 & $2-4$ & mixed \\
\hline 8.48 & 29 & 23 & 48 & 70 & 6 & $2-8$ & mixed \\
\hline 7.97 & 21 & 37 & 42 & 70 & 5 & $2-13$ & mixed \\
\hline 8.48 & 32 & 33 & 35 & 60 & 5 & $2-17$ & mixed \\
\hline
\end{tabular}


tested from time to time. Thus the last trials recorded in part 2 of the table were all made on the same group of animals, with the exception of two cases the oxygen content of the water was high and in all cases the amount of carbon dioxide present as free carbon dioxide was very small, so that these changes in reaction are not due to a modified gas content of the water.

It will be seen in later experiments, that the degree of positiveness depends upon the metabolic rate of the animals. That is, in animals having a high rate of metabolism there is a high positive response. From this point of view the decrease in the positive responses would be accounted for by assuming that the animals are in a state of lowered metabolism during the breeding season. This view is supported by those plants and lower animals that reproduce asexually during conditions favorable for growth and respond to poorer external conditions by sexual reproduction.

The cause of the variation in response is not impossible of solution although at present it cannot be treated entirely from the experimental side. From the results given it is evident that during the breeding season not all isopods are in the same physiological condition at any one time. The results from any one day as listed in the table show wide variations, yet these were taken from almost identical external conditions, so the variable quantity in this case must be an internal one. This view is further supported by comparing those results where the animals were in the copulating position. This term is used in the table to show when the females were being carried by the males. There are three cases given when all the individuals tried were in this position. Of these one gave a positive response of 11 per cent, another of 70 per cent, and the third gave no positive response at all. The first were taken from a very low oxygen content and as will be seen later this tends to decrease the positive response. Yet with this added complication they gave a much higher response than did two pairs taken the same day from another place in the same stream. It may be that in the case where no positive response was given the animals were near the actual copulation time, and the animals giving the 70 per cent response may have been far from this period. 
The large brood pouch on the ventral side of the females offers a serious mechanical obstacle to making progress against a strong current, but since the same reaction tendencies occur in the males this mechanical hindrance cannot be the only factor in the response. The condition of the germinal glands during the breeding season and the exact connection existing between their activity and the rheotactic response will be presented in detail in another paper.

In comparison with the normal behavior, the large increase in indifference to the current is remarkable, since this is just the condition that tends to prevail in pond animals. The action in the current is also decidedly different. The animals are much more easily swept from their footing; they do not reverse so rapidly as the current changes, often failing to reverse at all and the speed of reaction is greatly lowered. In some cases there is no response at all; the animals are then in the same state as that caused by the strongest depressing agents.

This breeding behavior brings up some interesting points in the ecology of the isopods. Although they are taken in streams they are rarely found in rapid parts of permanent ones, being limited for the most part to the pools and protected places. Outside of the breeding season they are fitted by their positive reaction to the current and their strong clinging ability to maintain themselves in much stronger currents than those in which they are found. The reason for their absence in these places must be due to the influence of the breeding activities upon their behavior. This is especially significant since their period of least ability to maintain themselves corresponds to the time of the strongest current in the stream. Hence their breeding behavior limits them to those streams where they can find ample lodging places during this time of weakened responses.

\section{c. Juvenite mores}

When the isopods are first liberated they are about $2 \mathrm{~mm}$. in length and usually give no response to the current but cling passively to the bottom. Consistent rheotactic responses were made by the time the animals were about $3 \mathrm{~mm}$. long; that is when 
they were about a month old. As table 4 shows, the general positive response of the young isopods is much lower than that of the adults but that the positiveness increases with age.

Again there is more variation in the positive response than seems consistent, for, as the table shows, the isopods give at times a low response regardless of size and of the external conditions here controlled.

It will be noted that the increase in positive reaction was not due primarily to the oxygen content of the water because this was high when the positiveness was low. The carbon dioxide was also low as it has been in all cases discussed. Evidently the growth in size was the most important factor in the increased positive response.

TABLE 4

Rheotaxis in juvenile stream Aselli

\begin{tabular}{|c|c|c|c|c|c|c|}
\hline SIZE & $\mathrm{O}_{2}$ & & RESPONSE & & $\begin{array}{l}\text { NUMBER OF } \\
\text { TRIALS }\end{array}$ & $\begin{array}{c}\text { TEMPERATURE } \\
\text { C. }\end{array}$ \\
\hline$m m$ & cc. per liter & per cent + & per cent - & per cent $\propto$ & & \\
\hline 3.5 & 6.26 & 33 & 67 & 0 & 40 & 17 \\
\hline 4.0 & 7.28 & 8 & 88 & 4 & 50 & 21 \\
\hline 4.0 & 5.63 & 16 & 84 & 0 & 25 & 17 \\
\hline 4.0 & 5.63 & 40 & $\cdot 36$ & 24 & 50 & 20 \\
\hline 4.0 & 6.55 & 42 & 48 & 10 & 30 & 17 \\
\hline 5.0 & 7.28 & 14 & 80 & 6 & 50 & 21 \\
\hline 5.0 & 7.28 & 30 & 68 & 2 & 50 & 21 \\
\hline 5.0 & 5.01 & 40 & 50 & 10 & 50 & 12 \\
\hline 5.0 & 5.23 & 45 & 52 & 3 & 40 & 21 \\
\hline 5.0 & 6.38 & 55 & 20 & 25 & 20 & 17 \\
\hline 5.0 & 6.94 & 60 & 30 & 10 & 50 & 15 \\
\hline 5.5 & 5.63 & 19 & 75 & 6 & 80 & 23 \\
\hline 5.5 & 7.06 & 50 & 40 & 10 & 60 & 22 \\
\hline 5.5 & 7.06 & 55 & 36 & 9 & 80 & 22 \\
\hline 6.0 & 5.63 & 16 & 84 & 0 & 90 & 23 \\
\hline 6.0 & 5.63 & 15 & 75 & 10 & 60 & 17 \\
\hline 6.0 & 8.19 & 32 & 14 & 54 & 50 & 8 \\
\hline 6.0 & 5.23 & 45 & 52 & 3 & 40 & 21 \\
\hline 6.0 & 6.57 & 90 & 7 & 3 & 40 & 22 \\
\hline 6.5 & 7.00 & 88 & 6 & 6 & 50 & 23 \\
\hline 6.5 & 1.14 & 92 & 0 & 8 & 50 & 29 \\
\hline 6.5 & 1.14 & 60 & 28 & 12 & 50 & 20 \\
\hline 8.0 & 5.23 & 56 & 42 & 2 & 50 & 21 \\
\hline 8.0 & 6.36 & 75 & 25 & 0 & 40 & 19 \\
\hline 8.0 & 4.27 & 90 & 5 & 5 & 20 & 21 \\
\hline
\end{tabular}


The importance of this factor is emphasized by the two trials where with a low oxygen content the animals tested gave a high positive response. This is the one case in the progress of this work where the laboratory tests have failed to run parallel with the field results, for as will be seen later, keeping young stream Aselli in water having a low oxygen content kept the animals from developing a high positive response, in all the cases tried. These two high results were obtained in the field on July 4, 1911. The stream at this time was reduced to a series of small pools with no running water, and in the case of the higher response, the animals were in a very high temperature, $29^{\circ} \mathrm{C}$., which may to some extent account for the difference between the two trials. Reference to this will be made in another part of this paper in connection with experimental data which may tend to clear up the case.

\section{d. Response to straight current}

Banta ('10, pp. 467-468) described a trough which he devised for testing the response of isopods to a straight current. His apparatus consisted of a simple straight trough in which the current was equalized by passing through a number of wire screens before it reached the experimental part of the trough. He introduced the isopods to be tested into still water and then turned on the current. After some crawling back and forth the animals collected at the upper end and stayed there from fifteen minutes to two days, afterward reversing their reaction.

In order to test the efficiency of the pan response as an index of the rheotactic activity of the isopods, Banta's experiments were repeated. A different type of trough was devised and is shown in figure 2. This trough has a rounded well $10 \mathrm{~cm}$. in diameter.

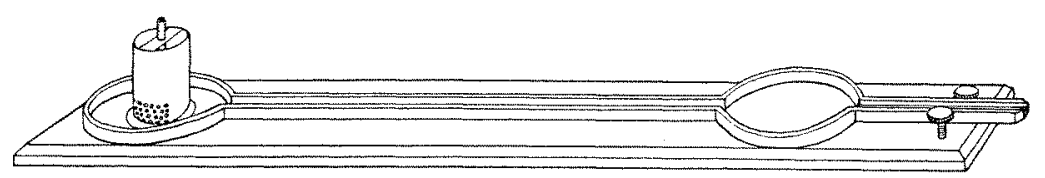

Fig. 2 Straight current apparatus 
The water is introduced through a circular tube $3 \mathrm{~cm}$. in diameter, which has holes to permit the exit of the water only on the side away from the trough. The trough is $3 \mathrm{~cm}$. across, $2 \mathrm{~cm}$. deep, and $50 \mathrm{~cm}$. long. At its lower end it opens into another well exactly like the one at the upper end. This in turn opens into a drainway directly below the end of the main trough, the drain being $1 \mathrm{~cm}$. above the general floor of the apparatus. The whole trough is made of wood and is painted a dead black with waterproof paint. Thanks to the careful workmanship of Mr. Floyd of the Ryerson Physical Laboratory, the trough is very accurate in its dimensions. The animals were confined by wire gauze and their movements measured by means of a centimeter scale at the top of one side of the trough. When in use the apparatus was kept almost level.

The animals to be experimented upon, were placed in the current at the center of the trough. They usually started off in the direction in which they were first headed regardless of the response which they would ultimately make. In some cases positive animals would continue with the current to the lower end and then turn and make their way back along the edge of the trough, toward the upper end. Usually they did not collect in contact with the upper screen as Banta found to be the case in his experiments. Rather the response brought a majority to the upper part of the trough where they settled in the angles between the bottom and the sides, with some of course clinging to the screen. In taking readings the exact position of each individual was recorded and an average taken of the position of the whole group. From five to eight was found to be the most convenient number to be tested at one time. A summary of the results obtained in this manner, with normal stream Aselli, is found in table 5 .

Often the isopods would move first up stream and then down stream, without giving a definite reversal. In these cases the reversal time was taken to be the time after which there was no decided movement against the current. When the experiments ran over night no readings were taken after midnight. Except in the third and last experiments recorded in the table there was 
TABLE 5

Stream Aselli in straight current

\begin{tabular}{|c|c|c|c|c|c|c|}
\hline \multirow{2}{*}{$\mathrm{O}_{2}$} & \multirow{2}{*}{$\begin{array}{l}\text { TIME BEFORE } \\
\text { REVERSAL }\end{array}$} & \multirow{2}{*}{ RESPONSE } & \multirow{2}{*}{$\begin{array}{l}\text { LENGTH OF } \\
\text { EXPERIMENT }\end{array}$} & \multirow{2}{*}{$\begin{array}{l}\text { CURRENT } \\
\text { STRENGTH }\end{array}$} & \multicolumn{2}{|c|}{ TEMPERATURE } \\
\hline & & & & & Trough & Aquarium \\
\hline cc. per liter & . & per cent + & & $c c$. & & \\
\hline 9.24 & after $2: 01$ & 84 & $3: 06$ & 1680 & 6 & 7 \\
\hline 9.21 & $2: 47$ & 78 & $3: 59$ & 1680 & 17 & 7 \\
\hline 9.52 & after 5:00 & $54^{*}$ & $15: 52$ & 1000 & 5 & 8 \\
\hline & $5: 30$ & 70 & $29: 28$ & 1020 & 5 & 8 \\
\hline 9.03 & $7: 40$ & $7 / 4$ & $29: 37$ & 1050 & 8 & 10 \\
\hline 5.13 & $23: 48$ & 64 & $59: 48$ & 1050 & 7 & 10 \\
\hline 6.33 & $11: 45$ & 58 & $35: 15$ & 1020 & 12 & 15 \\
\hline & $5: 17$ & $32^{*}$ & $44: 47$ & 1030 & 14 & . 14 \\
\hline 4.33 & $4: 35$ & 60 & $5: 17$ & 1100 & 16 & 16 \\
\hline & $6: 40$ & 77 & $24: 07$ & 1050 & 16 & 16 \\
\hline 7.00 & $6: 13$ & 78 & $10: 35$ & 1250 & 18 & 18 \\
\hline 6.85 & $5: 20$ & 78 & $7: 45$ & 1100 & 17 & 16 \\
\hline 6.77 & after $7: 00$ & 86 & $26: 20$ & 1050 & 13 & 15 \\
\hline
\end{tabular}

* Pan response taken after trough reversal; all others were taken before. The first column gives the oxygen content of the water in ce. per liter. The second gives the time in hours and minutes before there was a decided reversal in the response to the current. The third column shows the percentage of positive responses of the same animals to the circular pan current. The fourth column shows the duration of the experiment in hours and minutes. The strength of the current is given in cubic centimeters of flow per minute, the trough being placed as nearly level as possible. In the three cases where no exact amount of oxygen is shown, the amount present was well above air saturation at the given temperature.

no appreciable change of position during this period when no readings were taken.

A study of table 5 will show that there is a relatively long lapse of time before reversal. This length of time is correlated with the high per cent of positive responses. This correlation is by no means close, nor does it follow the fluctuations of the pan response but the significance of the relation between the two is well shown by comparing the results obtained here with those of isopods kept in water having a low oxygen content. 


\section{POND ASELLI}

\section{a. Adults}

As has already been mentioned, there are two species of isopods found in the ponds near Chicago. Mancasellus danielsii (Richardson, '05, pp. 417-419) has been previously reported from Laporte, Indiana, only. It is a much flattened form and is generally found in the grasses in the shallower water of the ponds. Its reactions so far as tested agree with those of $\mathrm{A}$. communis and unless otherwise designated all the discussion of pond behavior will be based on the latter species.

The pond Aselli are decidedly smaller than those from the stream. In the isopods that have been measured the difference averaged about $3 \mathrm{~mm}$., that is they were about 75 to 80 per cent of the length of the stream forms. However as has already been stated the pond isopods contain all the variations of the propodus of the first pair of legs that are to be found in the stream forms. The pond isopods react to light, heat, touch, and gravity in much the same way as the stream animals, although the speed of the reaction and the sensitiveness to the stimuli are probably different. The rheotactic response of the isopods from the two habitats is markedly different. In place of the positive reaction to the current dominating as in the stream mores, these isopods give a high proportion of indefinite responses. Their orientation is less definite and they do not appear to be so capable of ho ding an orientation once it is attained. Their response is less vigorous than that of the stream isopods and they are much more easily swept off their feet by the current.

A typical pond isopod response to current is shown in figure 3. This trial and record was made exactly like that for the stream isopod shown in figure 1. The result of twenty trials is given in which the animal went positive 25 per cent, negative 30 per cent, and indifferent to the current 45 per cent of the total number of trials.

The same response is shown in table 6 . It will be noted that the table includes the response made during the breeding season and that this response is not markedly different from that of the 
rest of the year although it is somewhat less positive. That is, the depression found in the stream Aselli during the breeding season is not so marked in the pond isopods.

The external condition with which the low positive response seems to be correlated is the low oxygen content of the water.

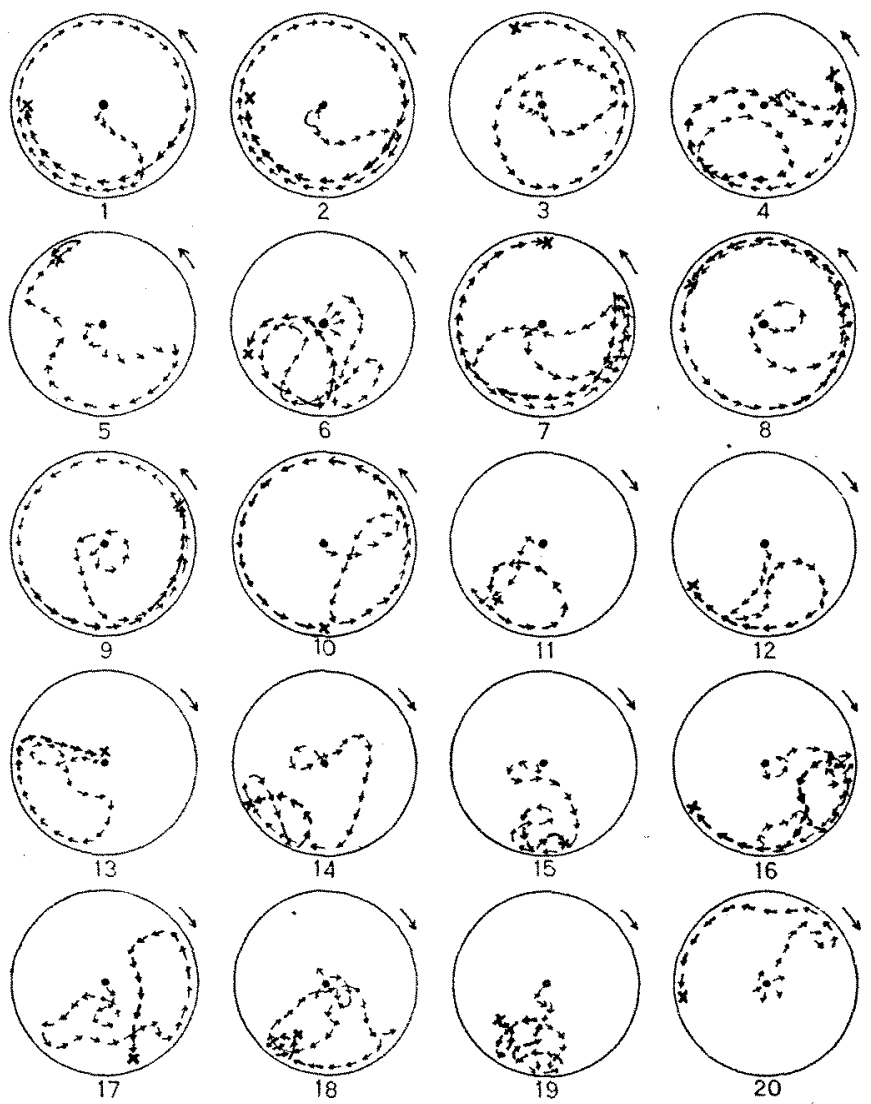

Fig. 3 Twenty suceessive rheotactic reactions of one pond Asellus

Thus the highest oxygen content of the pond is a little below the lowest found in the stream during a period of normal response, while the normal amount of oxygen found in the pond water is much below that of the stream. The amount of free carbon dioxide present in the pond water is higher than in the stream, but 
TABLE 6

Rheotactic response of adult pond Aselli

\begin{tabular}{|c|c|c|c|c|c|c|c|}
\hline $\mathrm{O}_{2}$ & & RESPONSE & & $\begin{array}{c}\text { NUMBER } \\
\text { OF TRIALS }\end{array}$ & $\mathrm{CO}_{2}$ & $\begin{array}{l}\text { TEMPER- } \\
\text { ATURE }\end{array}$ & REMARKS \\
\hline$c c . p e r$ liter & percent + & percent - & per cent $\propto$ & & cc. per liter & & \\
\hline 2.17 & 16 & 24 & 60 & 50 & $29^{\circ}$ & 3 & in lab. 14 hours \\
\hline 2.17 & 5 & 23 & 72 & 40 & 29 & 8 & 24 hours later \\
\hline 1.57 & 18 & 16 & 66 & 50 & 31 & 12 & in lab. 33 hours \\
\hline 5.04 & 36 & 34 & 30 & 50 & 14 & 15 & \\
\hline 2.28 & 17 & 19 & 64 & 80 & 9 & 13 & field: all males \\
\hline 2.28 & 19 & 21 & 60 & 80 & 9 & 13 & $\begin{array}{l}\text { field: all } \\
\text { females }\end{array}$ \\
\hline 2.28 & 8 & 20 & 72 & 25 & 9 & 13 & $\begin{array}{l}\text { field: conjugat- } \\
\text { ing }\end{array}$ \\
\hline 1.08 & 32 & 30 & 38 & 50 & & 13 & all with b.p \\
\hline 0.95 & 20 & 14 & 66 & 50 & 26.5 & 23 & $\begin{array}{l}4 \text { males: } 1 \text { fe- } \\
\text { male, b.p. }\end{array}$ \\
\hline 3.13 & 44 & 40 & 16 & 50 & & 22 & $\begin{array}{l}\text { close spring } \\
\text { breeding }\end{array}$ \\
\hline 2.33 & 20 & 48 & 32 & 40 & & 8 & $\begin{array}{l}7-25-11: \text { in ice } \\
\text { chest }\end{array}$ \\
\hline 3.66 & 36 & 48 & 16 & 50 & & 15 & $10-8-11$ \\
\hline 4.49 & 35 & 50 & 15 & 60 & & 6 & $10-28-11$ \\
\hline 1.25 & 32 & 28 & 40 & 50 & & 18 & lab. 10-19-11 \\
\hline 1.53 & 38 & 28 & 34 & 50 & & 18 & lab. $11-28-11$ \\
\hline 2.41 & 25 & 30 & 45 & 775 & & & \\
\hline
\end{tabular}

different sources of evidence tend to show that this amount of carbon dioxide is not sufficient to account for the difference in behavior. This problem will be considered later under the experiments upon the effect of carbon dioxide.

\section{b. Juvenile pond isopods}

The young isopods were tested for their response to current when they were about forty-five days old. At that time they were $3 \mathrm{~mm}$. in length. As was the case in the stream animals they gave a low positive response, behaving in almost every respect like stream isopods of the same size. But as will be seen in table 7 the later response did not show the increase in positiveness that was found in the developing stream forms. The other 
facts shown by the table support the experiments already discussed. The two responses marked 'M.d.' in the table show the reactions of juvenile Mancasellus danielsii. These trials were made in spring and summer and the two instances of lower temperature, are due to the animals being kept in an ice box. However, they were left in each case long enough to become thoroughly acclimated and so showed no effect of the continued low temperature.

\section{c. Response to straight current}

Only five trials have been made with pond isopods from water with a low oxygen content but as was the case in the stream animals these support the pan reactions, in that they show a short period of positive response to the straight current correlated with the low response in the pan reactions. A summary of the reactions is given in table 8 .

The conditions of the trials were exactly like those already described for this method. Owing to imperfect apparatus it was not possible to keep the temperature exactly the same in these trials and the variation in the second and fourth tests is enough to cause some difference in the response. In both cases this would tend to shorten the positive reaction if it acted in a

TABLE 7

Rheotaxis in juvenile pond Aselli

\begin{tabular}{|c|c|c|c|c|c|c|c|}
\hline SIZE & $\mathrm{O}_{2}$ & \multicolumn{3}{|c|}{ RESPONSE } & $\begin{array}{c}\text { NOMBER OF } \\
\text { TRIALS }\end{array}$ & TTEMPERATTURE & AGE IN DAYS \\
\hline$m m$. & cc. per liter & $\begin{array}{c}\text { percent } \\
+\end{array}$ & percent & $\begin{array}{c}\text { per cent } \\
\propto\end{array}$ & & & \\
\hline 3 & 2.5 & 20 & 39 & 41 & 70 & 19 & 40 (approx.) \\
\hline 8 & 0.95 & 3 & 7 & 90 & 30 & 23 & field test \\
\hline 3 & 2.33 & 23 & 36 & 41 & 100 & 24 & 56 \\
\hline 3 & 3.13 & 40 & 55 & 5 & 80 & 21 & 75 \\
\hline 4 & 3.24 & 24 & 60 & 16 & 50 & 25 & 122 \\
\hline 4 & 2.23 & 33 & 33 & 34 & 30 & 8 & 116 \\
\hline 5 & 3.24 & 14 & 57 & 29 & 50 & 25 & 122 \\
\hline 6 & 3.71 & 38 & 42 & 20 & 100 & 20 & 193 \\
\hline 4 & 3.13 & 32 & 56 & 12 & 50 & 22 & M.d. ${ }^{*}$ \\
\hline 7 & 2.33 & 20 & 6 & 74 & 80 & 8 & M.d. \\
\hline
\end{tabular}

* Mancasellus danielsii. 
TABLE 8

\begin{tabular}{|c|c|c|c|c|c|c|}
\hline \multirow{2}{*}{$\mathrm{O}_{2}$} & \multirow{2}{*}{$\begin{array}{c}\text { TIME } \\
\text { BEFORE } \\
\text { REVERAAL* }\end{array}$} & \multirow{2}{*}{$\underset{\text { PAN }}{\text { RESPONSE }}$} & \multirow{2}{*}{$\begin{array}{l}\text { LENGTH OF } \\
\text { EXPERY- } \\
\text { MENT }\end{array}$} & \multicolumn{2}{|c|}{ TEMPPERATURE } & \multirow{2}{*}{ PREVIOUS CONDIMIONS } \\
\hline & & & & Trough & Aquarium & \\
\hline \multicolumn{7}{|c|}{ cc. per liter } \\
\hline 2.17 & $\ddagger$ & 16 & $22: 92$ & 4 & 3 & in lab. 12 hours \\
\hline 2.17 & $0: 24$ & 5 & $1: 00$ & 4 & 10 & in lab. 40 hours \\
\hline 2.20 & 2.08 & 18 & 19.03 & 4 & 3 & $\begin{array}{l}\text { in lab. } 3 \text { hours } \\
\text { large males }\end{array}$ \\
\hline 5.04 & $1: 04$ & 36 & 2.55 & 5 & 15 & in lab. 18 hours \\
\hline 5.86 & $0: 41$ & $\dagger$ & $23: 36$ & 11 & 11 & $\begin{array}{l}\text { in tap water } 9 \text { days } \\
\text { b.p. }\end{array}$ \\
\hline
\end{tabular}

* Time before reversal and the length of experiment are given in hours and minutes; the pan response is in terms of the per cent of positive reactions. The current was kept at $1040 \mathrm{cc}$. per minute.

$\dagger$ With brood pouches unable to stay on bottom.

$\ddagger$ Almost no positive response at all.

direct way. But if there were a shock effect the result would be a lengthened response, so that perhaps the two might offset each other to some extent. Then, too, the experiments were in running water with a large amount of oxygen, because at this time there was no means of controlling the amount of oxygen present in water flowing at the rate used here.

The animals used in the first, second, and last trials were kept in running tap water for the length of time they had been in the laboratory. In the first two cases the animals were not exposed long enough to cause any effect upon their reaction, so the oxygen content of their original habitat is given. In the last trial the high oxygen evidently had not made any change in the response of the isopods, but this may have been due to the fact that these were females with large brood pouches that made it impossible for them to keep their footing in the strong current.

\section{SUMMARY OF RHEOTACTIC RESPONSE GIVEN UNDER NATURAL ENVIRONMENTAL CONDITIONS}

In discussing the normal rheotactic responses of $\mathrm{A}$. communis it has been shown that the same species is found in both ponds and streams, but that it is limited in the latter to those having 
quiet pools or other places of lodgement which keep the isopods from being swept down stream in the breeding season. The normal rheotactic reactions of animals from the two types of habitats are quite different. Animals from streams give a high percentage of positive responses; they are much more vigorous and definite in their reactions and show a long period of positive reaction in a straight current. The pond isopods on the other hand give a weak positive response and are much inclined to be indifferent to the current. They are less active than the stream mores, and in the straight current, they give only a short positive response.

The most obvious difference in the environment in the two habitats is the difference in the oxygen content of the water. In the streams this is normally between 5 and $10 \mathrm{cc}$. per liter depending on temperature, rate of flow, and the character of the stream. bed. In the ponds studied, on the other hand, the amount of oxygen present is low, seldom going above $3 \mathrm{cc}$. per liter at any period of the year. There is also a difference in the amount of free carbon dioxide present in the two habitats. This runs about 2 cc. per liter in the streams while in the ponds it has been taken as high as $40 \mathrm{cc}$. per liter, the usual amount however is about 10 to $15 \mathrm{cc}$. per liter. From this work alone it would seem probable, that the difference in positive response to the current in the two habitats may be due to the difference in the oxygen or carbon dioxide content of the water.

The main breeding season occurs in the spring of the year in both habitats. In the pond isopods, this does not affect the normal rheotactic response so markedly as with the Aselli from the stream. In these it causes a distinct lessening of the positive reactions so that for the time being, they behave as though they were pond isopods. The young from both habitats give a low positive response, but in the streams the reaction becomes more positive as the animals increase in size, while in the pond isopods it remains the same throughout life. 
III. RHEOTACTIC RESPONSE UNDER EXPERIMENTAL CONDITIONS

1. STREAM ASELLI

\section{a. With decreased oxygen}

The methods of handling the problem of confining the isopods in water having a low oxygen content, have varied more in the progress of this work than those in any other line. The first method tried was to keep the animals in an aquarium having no inflow of water and containing a large amount of dead leaves and other organic matter, which would absorb oxygen. This worked after a scum had appeared to hinder the absorption of oxygen from the air. Obviously, this method at best was crude, and after trying boiling and cooling water in ordinary vessels, which was of course very laborious, a machine for deaerating water was devised. This apparatus was devised and built by V. E. Shelford and the writer and will be described in detail elsewhere. In brief, it consists of a tower down which the water runs through successive sieves and is thus reduced to air saturation at the temperature used. Then the water is heated in aluminum pans over powerful gas flames until it is about to the boiling point. It is then cooled by passing through eoils of block tin pipe surrounded by tap water. In this way $1200 \mathrm{cc}$. of water can be treated each minute and the oxygen content reduced from $8 \mathrm{cc}$. per liter of water to less than half a cubic centimeter. By arranging the flow in the cooler any desired temperature can be obtained. A gas introducer permits the addition of oxygen or carbon dioxide to the deaerated water.

Since the completion of this device the best results with low oxygen have been obtained and most of the data to be given on this subject are from work done with water prepared in this way. The most important chemical changes due to the boiling, as shown in analyses by Mariner and Hoskins of Chicago, are seen in table $9 .^{2}$

In this work the animals to be used were first tested and then placed in glass jars with ground glass edges. A glass plate was

${ }^{2}$ The complete table will be published later. 
TABLE 9

The effect of the deaerating apparatus upon the salt content of the water. $A=$ Boiled in apparatus. $B=$ Hot tap water. $C=$ Cold tap water. Results are given in parts per 100,000

\begin{tabular}{|c|c|c|c|}
\hline & A & $B^{*}$ & $\mathrm{C}$ \\
\hline Nitrates. & 0.060 & 0.170 & 0.070 \\
\hline Iron...... & 0.011 & 0.015 & 0.006 \\
\hline Lime $(\mathrm{CaO})$. & 4.360 & 4.360 & 4.840 \\
\hline Magnesia (MgO). & 2.001 & 1.657 & 1.882 \\
\hline Sulphuric acid $\left(\mathrm{SO}_{4}\right) \ldots \ldots \ldots \ldots \ldots$ & 0.0071 & 0.003 & 0.004 \\
\hline Total solids. & 14.800 & 13.800 & 15.400 \\
\hline
\end{tabular}

In the experiments the hot water (B) from the University heating system was treated in the apparatus and the table shows that this treatment made it more like the ordinary tap water, as far as the contained salts are concerned.

used as a cover and was sealed down with vaseline, care being taken to avoid enclosing any air bubbles. In experiments that were run some time a few leaves were placed in the jar for food. The water was changed often enough to provide an even supply of oxygen.

(1) Normal adults. Table 10 shows the results of a number of trials in which, with the exception of no. 9, the oxygen content of the water was low at the time of the trial and had been low for at least ten days. The purpose of the table is simply to show the typical response of stream isopods that have been kept in low oxygen. It will be noted at once that the reaction is decidedly different from that of the normal stream Aselli, in that the positive percentage is lowered and the amount of indifference to the current is correspondingly increased. It is significant that the lowest positive responses are made by the animals in the lowest oxygen, and that above 3 ce. the response becomes more variable although in the main it increases as the oxygen supply increases. The reactions that are grouped under no. 9 in table 10, were given by isopods that had been in running water up until twelve days before this trial was made. At that time they were giving a 70 per cent positive response in an oxygen content of $5.92 \mathrm{cc}$. per liter. The water was turned off and three different trials made, with the results recorded. From the variation, this seems to be 
TABLE 10

The effect of low oxygen upon the rheotactic response of adult stream Aselli

\begin{tabular}{|c|c|c|c|c|c|c|}
\hline \multirow{2}{*}{\multicolumn{2}{|c|}{$\frac{\mathrm{O}_{2}}{\text { c. per liter }}$}} & \multicolumn{3}{|c|}{ RESPONSE } & \multirow{3}{*}{ 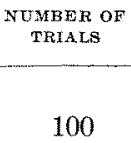 } & \multirow{3}{*}{$\begin{array}{c}\text { TEMPEATUVR } \\
18\end{array}$} \\
\hline & & \multirow{2}{*}{$\begin{array}{c}\text { per cent }+ \\
23\end{array}$} & \multirow{2}{*}{$\begin{array}{c}\text { per cent }- \\
35\end{array}$} & \multirow{2}{*}{$\begin{array}{c}\text { per cent } x \\
42\end{array}$} & & \\
\hline (1) & 0.23 & & & & & \\
\hline$(2)$ & 0.37 & 20 & 6 & 74 & 50 & $: 8$ \\
\hline (3) & 1.00 & 30 & 20 & 50 & 40 & 7 \\
\hline (4) & 1.90 & 20 & 44 & 36 & 50 & 17 \\
\hline (5) & 3.37 & 62 & 6 & 32 & 50 & 19 \\
\hline (6) & 3.50 & 46 & 44 & 10 & 50 & 17 \\
\hline$(7)$ & 3.58 & 38 & 35 & 27 & 100 & 15 \\
\hline \multirow[t]{2}{*}{ (8) } & 4.16 & 62 & 18 & 20 & 50 & 19 \\
\hline & & 56 & 40 & 4 & 50 & 9 \\
\hline \multirow[t]{2}{*}{$(9)$} & 4.44 & 60 & 30 & 10 & 50 & \\
\hline & & $77_{4}$ & 26 & 0 & 50 & \\
\hline$(10)$ & 4.50 & 47 & 28 & 25 & 60 & 19 \\
\hline (11) & 4.83 & 40 & 50 & 10 & 30 & 22 \\
\hline$(12)$ & 4.83 & 53 & 40 & 7 & 30 & 22 \\
\hline & 3.06 & 45 & 30 & 25 & 760 & \\
\hline
\end{tabular}

the breaking point in the reaction to current for these animals at this time. However if they had been accustomed to a lower amount of oxygen, they might have reacted positively when kept in this amount of oxygen. The effect of increasing the amount of oxygen is shown by the fact that after one day in $7.51 \mathrm{cc}$. oxygen per liter, these isopods gave an 82 per cent positive reaction.

Something of the details of the effect of a lowered amount of oxygen is shown in table 11 . The first set of results is taken from the early work. The amounts of oxygen did not rise, during the time shown in the table, above $4.5 \mathrm{cc}$. per liter nor fall below 2 cc. The effect of the lack of oxygen in this case became evident after the animals had been in quiet water for twentyfour days. An entry in the laboratory notes for that day reads as follows: "The reaction to current is slower, less definite, and is maintained for a shorter period than with "the freshly collected isopods." Unfortunately the exact oxygen content at that time is unknown. The most important thing shown by this section of the table is that the Aselli tend to become acclimated to the low oxygen and at length react with a normal amount of positiveness 


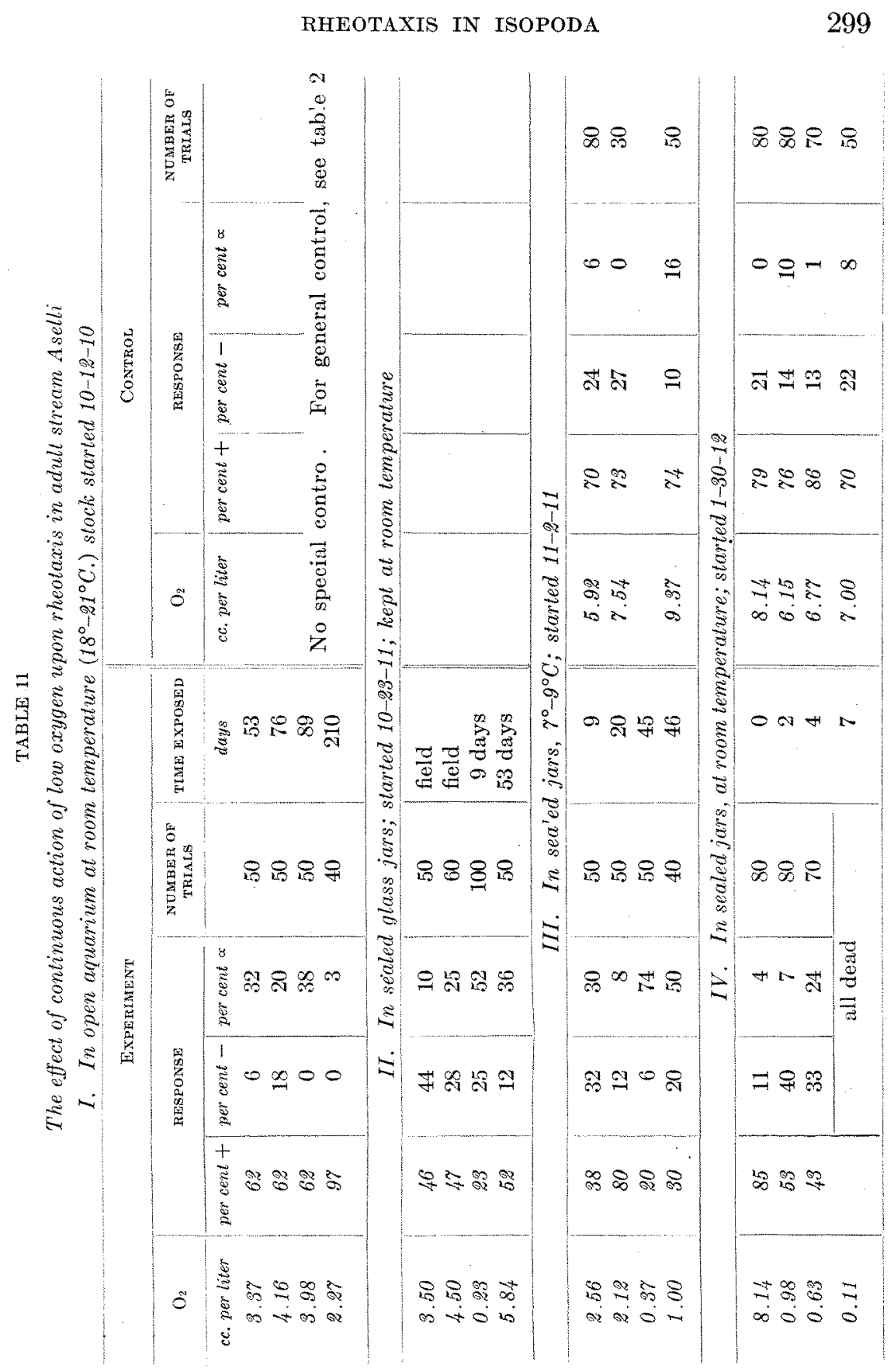


with an amount of oxygen that at first caused a decided lessening of the positive reaction. ${ }^{3}$

The second part of the table shows an interesting case of the correlation between the amount of oxygen present and the positive response of the isopods. The first two field trials show a medium amount of oxygen present and a correspondingly medium positive response. The third trial shows the effects of nine days in the laboratory in which time the oxygen had been almost all used and the positive response is halved as a result. Then with an increase in the amount of oxygen, the positive reaction increased. In both of these cases the control was furnished by keeping the same animals in running water, and as was seen in table 2, those isopods stayed positive throughout as far as oxygen was concerned.

In the next two parts of the table, however, the control was kept under exactly the same conditions as the experiment, except as regards the oxygen content. Part 3 shows both the acclimatization effect and the dependence of the positive reaction upon the amount of oxygen present. Part 4 gives some idea as to the rate with which the effect of a lowered amount of oxygen may be reflected in the rheotactic response.

The amount of carbon dioxide free in the water was never high in these experiments. The highest record is that of $4.5 \mathrm{cc}$. per liter which occurred in the experiment given in part 1 of the table. In the last experiment given, the carbon dioxide did not rise above 1 cc. per liter in the experiment while in the control it was between 1 and $3 \mathrm{cc}$. to the liter. Neither can the boiled water have been a factor in these changes, for the isopods used in the last case, both control and experiment, had been kept for a month in the boiled water that had been saturated with oxygen by absorption from the air. For that matter, the reactions given in table 1 were given by isopods from this reaerated boiled water, and it will be remembered that their reactions averaged 89.4 per cent positive.

\footnotetext{
${ }^{3}$ Haldane and Smith ('97, p. 250) report a similar acclimatization occurring in mice when subjected to a decreased oxygen tension.
} 
From these results it will be seen that a decrease in the oxygen supply decreases the positive response of the isopods to current and that this decrease may be only temporary, or in other words that the Aselli may become acclimated to the new conditions and give a high positive response in an oxygen content that at first caused a marked decrease in their normal reactions. However, at no time in the progress of these experiments, have the isopods showed any sign of an acclimatization when kept in an oxygen content of about 1 cc. per liter. Thus the stream isopod if kept continuously in the average amount of oxygen to be found in the ponds would in time come to respond positively to currents under the new conditions, yet, if they were subjected to the extremes of low oxygen that are sometimes maintained for fairly long periods of time, there is no evidence that adults would ever become acclimated.

These results are of importance when considered in the light of the conditions which the stream isopods may have to meet in nature. As has already been said, they live in pools of small streams. In summer these streams sometimes cease to run and in this condition, the pools often take on the characteristics of a pond for the time that the condition lasts. The cycle of reactions under these conditions is easily seen. The isopods used to a supersaturated oxygen supply would become less positive to a chance current as the pool water became low in oxygen. Then unless the deoxygenation went too far, there would be an acclimatization so that on the average when the stream began flowing again the isopods would be positive to the current and would thus be better equipped to escape being carried out of the stream. Of course even when they are negative to the current, many would be kept in the stream by being stranded against piles of drift.

(2) Breeding season. But one controlled experiment was run on the effect of lowered oxygen supply on the breeding season response, but this appears significant in that the experimental results confirmed the prediction that was made concerning them. They also ran parallel with the effect of an increase in the amount of carbon dioxide as will be shown in a later section. The animals used in this experiment were large males about $15 \mathrm{~mm}$. in 
length. All were as near the same size and general condition as could be selected from their external appearance. The stock had first shown signs of the approach of the breeding season in the latter part of December and these trials were begun January 31,1912 , so that at that time they were in the midst of the breeding season.

The isopods were taken from a temperature of $4^{\circ} \mathrm{C}$. and with the exception of the first trial in the control they were kept within two degrees of this temperature throughout the experiment. The heightened response obtained from the control in their first trial may be due to the fact that the temperature was $4^{\circ}$ above that to which they were accustomed, or it may mean that the isopods used were not so completely under the influence of the breeding response as they became later. It will be noted that during the time the experimental animals were giving a changed reaction, the control gave almost no variation in response.

In the experiment the variation in the first two days is not strong enough to make one sure of the cause without more data, but at the end of the third day there is a strong increase in the positive reaction which is entirely different from anything that we have yet seen in the response to a sudden lowering of the oxygen content of the water. This increase in positiveness was maintained three days in which time it had increased until the response was almost that of the normal adult isopod under high oxygen conditions. Then the response fell off and at the end of the experiment it was decreased almost to the zero mark. This decrease started at the time of the highest oxygen supply so that it was not due to the variation of the amount of oxygen present.

The following explanation of these phenomena is suggested. When the breeding activity set in, energy normally spent in general body metabolism is taken by the reproductive organs. As these increase in activity, the amount of energy left for bodily activities decreases and hence the positiveness of the animals to currents of water is diminished. But the presence of an external medium tending to decrease the rate of metabolism decreases that of the reproductive system and so gives an increased amount of energy for bodily activities. This results in an increase of the 


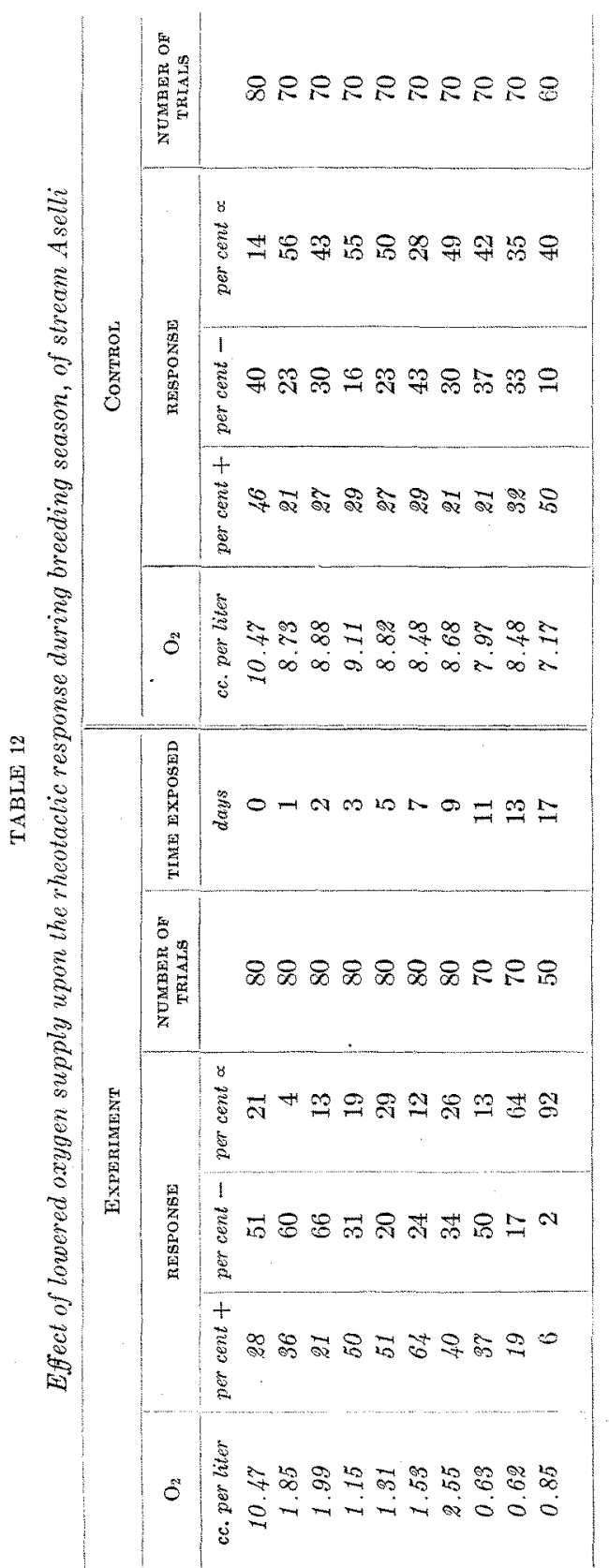


positive response. Later if the external depressing factors are continued in their action, the rate of metabolism is cut below that which supplied energy for the body alone and this results in a decrease in positiveness below that usual in the breeding season. Besides being supported by the rheotactic response this hypothesis is supported by the fact that the isopods tend to lose their general breeding reactions if kept in a decreased oxygen supply. The hypothesis is capable of being experimentally investigated, and this is one of the points upon which the writer expects to do further work.

(3) Juvenile stream Aselli. It has been shown in dealing with the rheotactic response of juvenile stream isopods in the field (table 4) that in at least one case the Aselli are known to have given an increase to a strong degree of positiveness in the presence of a small amount of oxygen. All the tests that have been carried on in the laboratory have failed to give a corresponding result. These experiments are of two kinds. First, the less carefully controlled type of experiments that characterized the early part of the work. In these experiments the actual amount of oxygen present in the water was not under control although it was always below air saturation at that temperature. Results from this type of experiment are shown in the first part of table 13. The other experiments were more carefully controlled and these results are shown in the second part of the same table.

In the first part of table 13 the results given for the response of the isopods under high oxygen conditions have been summarized from table 4 . That is, the average response shown in that table has been taken as giving the reaction of the isopods of that size under normal conditions. The oxygen content given is also the averaged amount shown for the same trials in the same table. It will be seen that until the isopods are about $5 \mathrm{~mm}$. long, they tend to give the same response regardless of the amount of oxygen supplied, but that after that size is reached, the animals with the higher oxygen supply increase much more rapidly than do the ones with a sub-normal supply. The figures in this case for the animals in the low oxygen content represent the entire life history of the isopods up to the time of their first breeding season. 
RHEOTAXIS IN ISOPODA

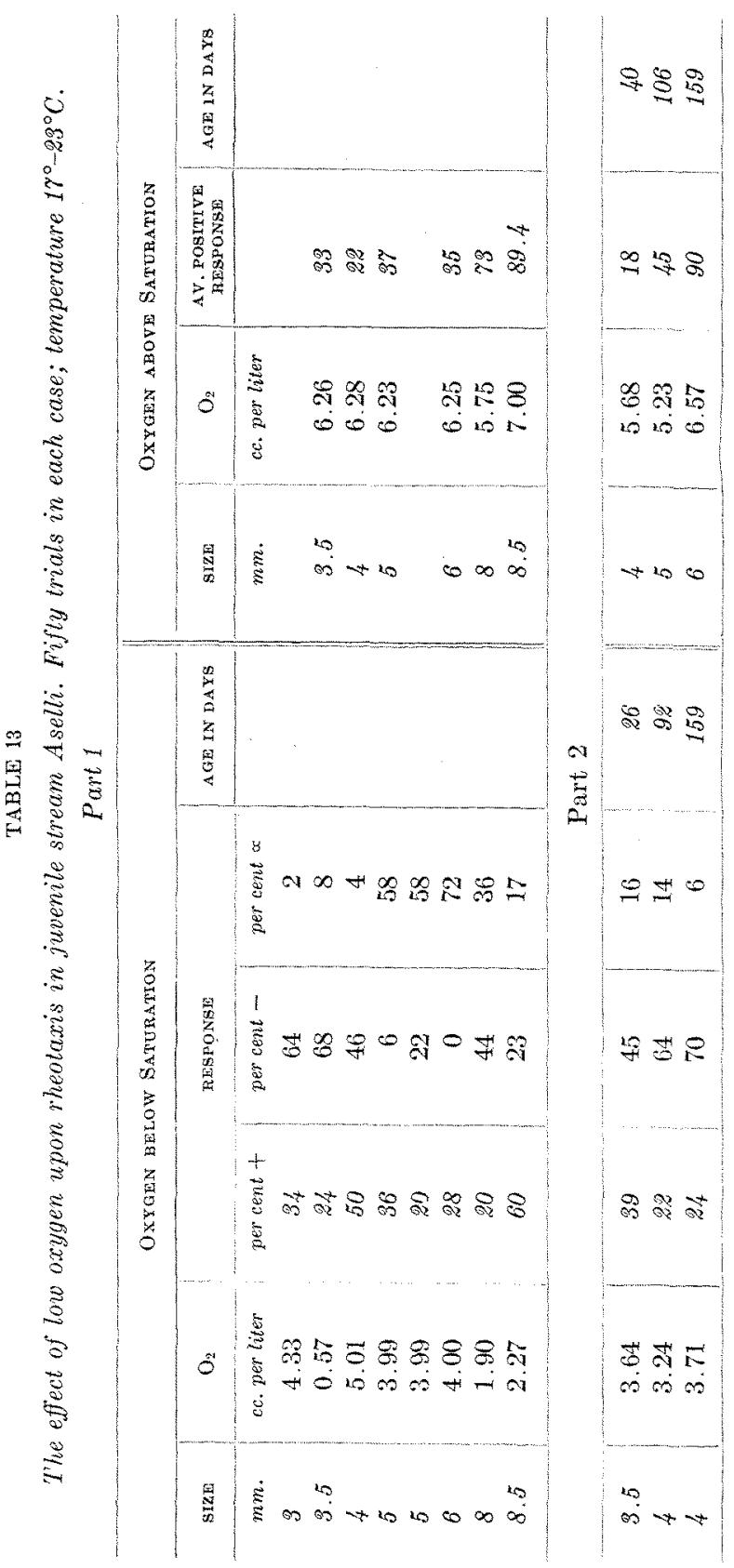


That is, in the isopods in low oxygen content all their lives, there was less tendency to regulate their response to that normal for stream isopods than was the case with their parents that were kept in the same vessel with the second generation. Another point is significant in this connection. The isopods in the smaller amount of oxygen were seven months old at the close of the trials shown in the table, while those in higher oxygen were only five months old. The exact meaning of this time difference is masked by the fact that the isopods in the low oxygen content had been kept in quiet water which was only infrequently changed, while the others were from running water. The food conditions in the two cases were about the same.

The second part of the table summarizes the results of more exact tests. The isopods used in both this experiment and the control were reared in the laboratory from the same stock. They were separated when too small to be tested and those that were to be kept in higher oxygen were placed in an aerating device patterned after that of Colton ('08, p. 428). In the form used this consisted of a large wide mouthed glass bottle which could be tightly sealed (fig. 4).

Two glass tubes extend through the cork. One of these $(B)$ opens above the water in the bottle and is connected at the other end with a filter pump. The other glass tube $(A)$ is drawn to a fine point at the outside end and only a small opening is left for the entrance of air. In this way the bubbles are smaller and so create less current in the water. On the inside this tube extends down well towards the bottom and opens into a larger tube $(C)$. The large tube is about two centimeters in diameter and slopes upward until its upper end extends out of the water. Just below the water's surface are three openings $(E)$ blown into the wall of the tube. When the suction is turned on, the air is drawn into the bottle through $(A)$. The bubbles are then drawn into $(C)$ at $(D)$ and escape at $(F)$.

During the passage through the water some of the gases of the air are absorbed and in this way the water is kept at air saturation. Whatever current is set up by the passage of the bubbles escapes through the holes $(E)$ on the under side of the large 
tube. In this way it is possible to keep water well aerated without setting up strong currents. In fact by adjusting the rate of flow of the bubbles and by keeping the tube from extending too far into the water it was found that scarcely any current was noticeable on the bottom of the container.

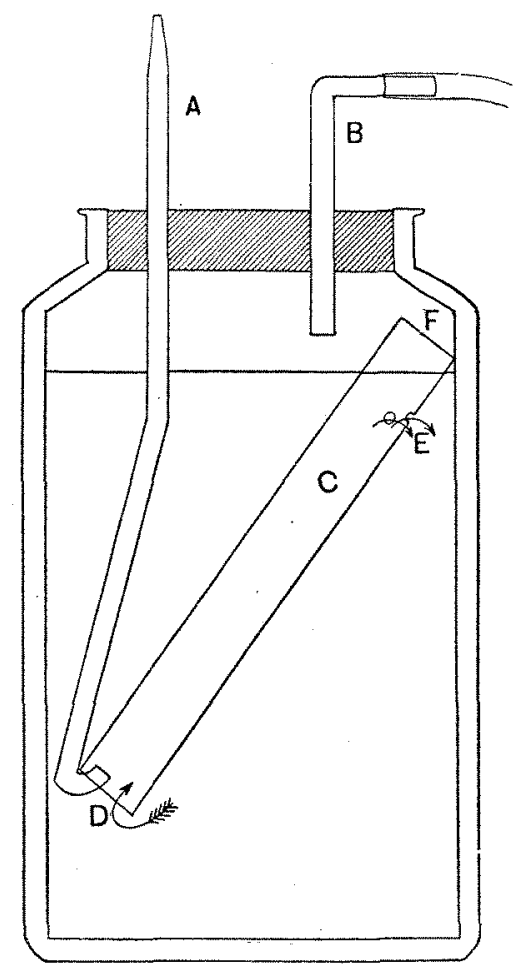

Fig. 4 Modified Colton aerating apparatus

This device has several advantages as a control in this kind of experiments, for it enables one to keep the isopods in a well-aerated, current-free medium. This avoids the possible mechanical stimulation of the current and at the same time keeps the isopods in the presence of their own waste products and thus in the same conditions as prevail in the experiment, except as regards the oxygen supply, and the possible increased oxidation of the waste. 
In the case of these experiments, the isopods were put into this aerating device in the water in which they had been reared and this water was not changed. From table 13 it will be seen that the isopods in the aerated water, not only responded to currents with a much stronger degree of positiveness, but that their rate of growth was more rapid. In this case the supply of oxygen is the only factor known to have varied.

(4) Response to straight current. The effect of keeping stream isopods in low oxygen is more marked if tested in a straight current, than when only the pan responses are compared. The lack of adequate apparatus in the early part of the work is more clearly shown in these experiments than when the pond reactions were being discussed. All of the trials except the second and fifth shown in table 14, were made before the later apparatus was built. In these cases it was impossible to control the oxygen supply or the temperature during the trough tests. It was therefore necessary to test the isopods from low oxygen and room temperature, in cold tap water having a high oxygen content. Under these conditions it is remarkable that the results in the rest of the table compare as well as they do with the results obtained under properly controlled conditions.

TABLE 14

Stream Aselli from low oxygen in straight current

\begin{tabular}{|c|c|c|c|c|c|c|c|}
\hline \multirow{2}{*}{\multicolumn{2}{|c|}{$\mathrm{O}_{2}$}} & \multirow{2}{*}{$\begin{array}{l}\text { TIME* BEFORE } \\
\text { REVERSAL }\end{array}$} & \multirow{3}{*}{$\begin{array}{c}\text { PAN } \\
\text { RUSPOAYEE }\end{array}$} & \multirow{2}{*}{$\begin{array}{l}\text { LENGTH OF } \\
\text { EXPERMMENT }\end{array}$} & \multirow{2}{*}{$\begin{array}{l}\text { CURRENT } \\
\text { STRENGTH }\end{array}$} & \multicolumn{2}{|c|}{ TEMPERATURE } \\
\hline & & & & & & Trough & Aquarium \\
\hline \multicolumn{2}{|c|}{ co. per liter } & & & & $c e$. & & \\
\hline (1) & 3.96 & $0: 28$ & 18 & $3: 47$ & 1680 & 17 & 18 \\
\hline$(2)$ & 3.57 & $0: 28$ & 28 & $26: 57$ & 1050 & 11 & 11 \\
\hline (3) & 3.80 & $0: 33$ & 69 & $4: 02$ & 1000 & 16 & 18 \\
\hline (4) & 4.00 & 0.57 & 28 & $2: 14$ & 1020 & 15 & 17 \\
\hline (5) & 0.57 & $1: 00$ & 43 & $3: 00$ & 1050 & 13 & 15 \\
\hline (6) & & $1: 03$ & 20 & $4: 19$ & 1000 & 18 & 13 \\
\hline (7) & 3.96 & $1: 12$ & 62 & $2: 28$ & 1680 & 5 & 18 \\
\hline (8) & & $1: 22$ & 36 & $2: 43$ & 1000 & 5 & 19 \\
\hline (9) & 2.28 & $1: 58$ & 20 & $18: 35$ & 1050 & 10 & 17 \\
\hline$(10)$ & 2.28 & $6: 23$ & 78 & $18: 35$ & 1050 & 10 & 17 \\
\hline
\end{tabular}

* As before, the time given is in hours and minutes. The pan response is stated in torms of the per cent of positiveness. The strength of the current is given in cubic centimeters of flow per minute. In the sixth and eighth trials the amount of oxygen was well below the point of air saturation. 
In the third, fourth, seventh and eighth trials listed the response was probably shortened by the change in temperature. In all but the second and fifth trials it may have been lengthened by the presence of a large amount of oxygen in the water. In spite of these difficulties the reactions are fairly consistent with the other straight current tests, that is there is an apparent correlation between the length of the positive response and the per cent of positive reactions in the pan tests. This means that the animals in the stream if caught in a sudden current, after a period of low oxygen in summer pools, would maintain themselves against the current for only a short time and must be washed down stream much sooner than isopods from the usual stream conditions.

If the low oxygen should be long continued, however, the animals would tend to become acclimated. This has already been shown to be true for the circular current and is illustrated here by the response given in the tenth trial shown in table 14. This response was given by the same isopods that showed acclimatization to the circular current in the first part of table 11.

\section{b. Carbon dioxide}

Not enough experimental work has been done on the effect of increasing the amount of carbon dioxide present in the water to enable this discussion to be critical. However, there are some lines of evidence that appear significant. In the streams the amount of carbon dioxide present in the free state is low, that is it averages from 2 to $3 \mathrm{cc}$. per liter. In the ponds it has been taken as high as 40 ce. per liter but the average is about one-fourth this amount. Since water will absorb over $900 \mathrm{cc}$. of carbon dioxide per liter, it will be seen that only a relatively small amount is present even in the ponds.

Part 1 in table 15 gives the effect of low oxygen and increased carbon dioxide, the latter being present in the amount that was found in nature in the most extreme cases. The positive rheotactic response gradually fell under these conditions, but by referring to table 11 , part 4 , it will be seen that the decrease is not so rapid as when only low oxygen was acting. The second part of the table gives the effect of a much larger amount of car- 


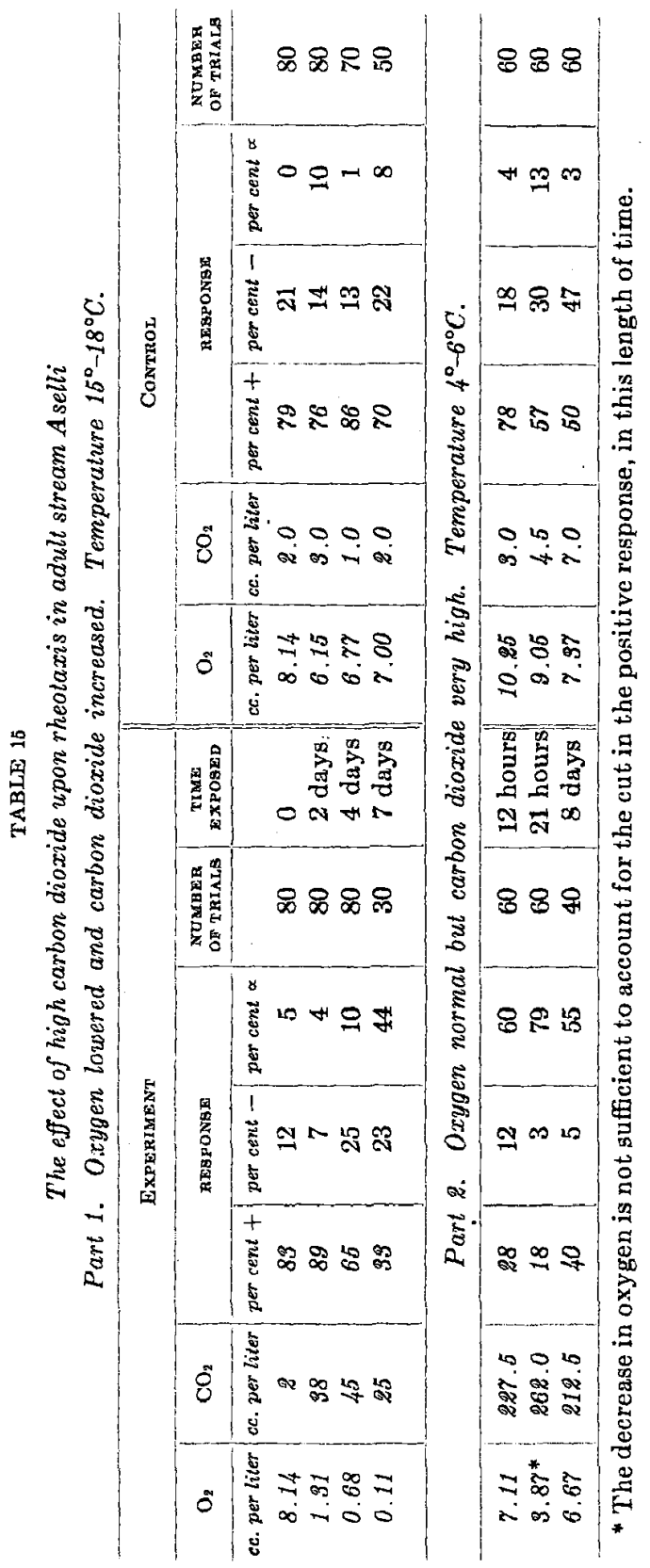


bon dioxide than has been found in any isopod habitat so far studied. In this case the action of the carbon dioxide in twelve hours cut the positive reaction to 28 per cent, while the control in low carbon dioxide stayed at 78 per cent. The control and experimental animals were then changed. In twenty-one hours the isopods in the experiment gave an 18 per cent positive response while those that had been changed from the experiment to the control had increased from 28 to 57 per cent positive. The lowering of the oxygen in this case is due to bubbling the carbon dioxide through the water in order to increase the amount of carbon dioxide present.

Eight days later the response in the two conditions was about the same but the breeding season had set in and one pair of the control animals was copulating. This complication makes the cause of the increased response in the experiment problematical. It may be due to acclimatization, or to an interaction of the carbon dioxide and the breeding season, similar to that given with decreased oxygen.

Part 1 of table 16 shows two experiments run during the breeding season of 1911. The first was started April 6, and the second twenty-four days later. The presence of the carbon dioxide caused an increase in the positive rheotactic response from 38 to 58 per cent in that time. In the second experiment the control animals increased their positiveness due to the close of the breeding activities, and the animals in the increased amount of carbon dioxide did the same, although there was twice the amount of carbon dioxide present that was ever found in the ponds studied.

The second part of table 16 gives the results of experiments run at the same time as those given for low oxygen in table 12 . In this case there was first a slight increase followed by a decrease in the positive rheotactic response, and as the amount of carbon dioxide was increased the positive reaction decreased. The increase in positiveness however was not so great as that given with low oxygen under similar conditions.

The results obtained correspond exactly with the known effects of carbon dioxide as a drug. Cushny ('10, p. 588) says in part, that in mammals, carbon dioxide unmixed with oxygen produces 


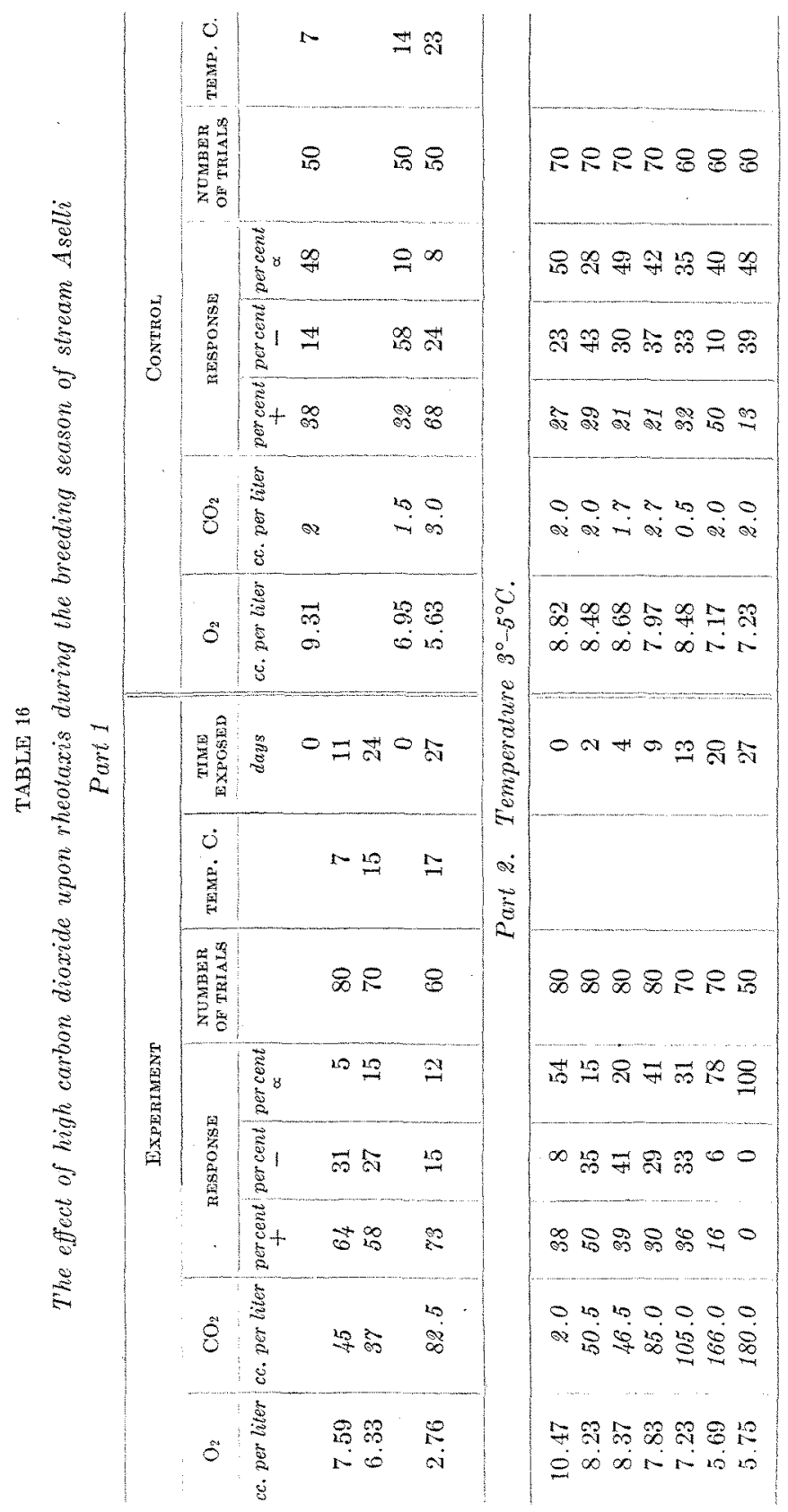


asphyxia, partially due to a lack of oxygen and partially to a direct depressing action upon the central nervous system. When mixed with sufficient oxygen the specific effects of the gas may be observed without asphyxia. Under these conditions transient stimulation occurs, followed by subsequent depression of the central nervous system and heart. In well diluted vapor, only the exaltation occurs as the anesthesia does not follow. This would mean that the results shown in the first parts of tables 15 and 16 are due to the action of carbon dioxide as a stimulant, and this may even retard the depressing effect of a decreased oxygen supply (table 11, part 4). But when over $200 \mathrm{cc}$. of carbon dioxide per liter are present, it acts as a strong depressant. Regarding the effect of large quantities, Cushny (1.c., p. 588) says that in mammals a large amount of carbon dioxide probably acts as a poison to protoplasm, for it lessens the amount of oxygen absorbed, so that in the final analysis it would seem that the depressing effect of carbon dioxide is directly due to increased oxidations and thus it acts in the same way as when the supply of oxygen is decreased.

It will be remembered that the free carbon dioxide present in the streams is about $2 \mathrm{cc}$. per liter, while that of the ponds may run as high as $40 \mathrm{cc}$. But since in the experiments $45 \mathrm{cc}$. of carbon dioxide acts as a stimulant, and since small amounts of the gas are known to be mammalian stimulants, it is improbable that the low positive response of pond isopods is correlated with the increased carbon dioxide content of the water. This then leaves the decreased oxygen supply as the main environmental factor with which the lowered positiveness seems correlated.

\section{c. Chloretone}

Chloretone (acetone chloroform) belongs to the class of substances commonly known as anaesthetics. Authorities generally agree that these anaesthetics inhibit to some extent certain of the fundamental metabolic reactions (Child, '10, p. 173). Different strengths of chloretone were used in these experiments but 0.005 per cent was found to work best for experiments that were to run some time. Preliminary tests showed that the animals collect 
in bunches when first placed in a solution containing chloretone. Later they became acclimated and moved more normally but would bunch again if more chloretone was added. As has been previously stated, this reaction is also induced by a sudden increase or decrease in temperature.

The exposure to chloretone for the rheotactic experiments was made in sealed glass jars, the solution being changed every twentyfour hours. The results of one experiment only are shown, (table 17) but these are entirely comparable to the reactions given by a number of other tests. In this experiment the control animals remained strongly positive while the reaction of those under the influence of chloretone was cut from 78 to 25 per cent positive. Towards the end of the experiment the animals were evidently becoming acclimated and hence gave a normal response.

\section{d. Potassium cyanide}

Potassium cyanide is known to decrease the amount of oxidations by decreasing the ability of the tissues to take up oxygen. (Geppert, '99, p. 208). Then weak solutions of this chemical should show the same results upon isopod reactions as keeping them in a low oxygen supply. Experiments prove this assumption to be true. The results of two series of such experiments are shown in table 18. These experiments were conducted in every respect like those with chloretone. The amount of potassium cyanide used gave only a faint odor to the water.

In the first part of the table, isopods giving a positive pan response of 82 per cent, were placed in $\mathrm{N} / 100,000 \mathrm{KCN}$ solution. At the end of five days they gave a 30 per cent positive response. For the next three days they were kept in $\mathrm{N} / 125,000$ solution and during that time the response was practically the same. At the end of eight days half of the original number were dead. The remainder were put in tap water and showed a rapid recovery of their normal response. The other trial shows the same results except that when the experiment ended, all but two of the isopods were dead. The lowering of the positive response in the control is due to the fact that the control in these experiments was run with very.little food. 
RHEOTAXIS IN ISOPODA
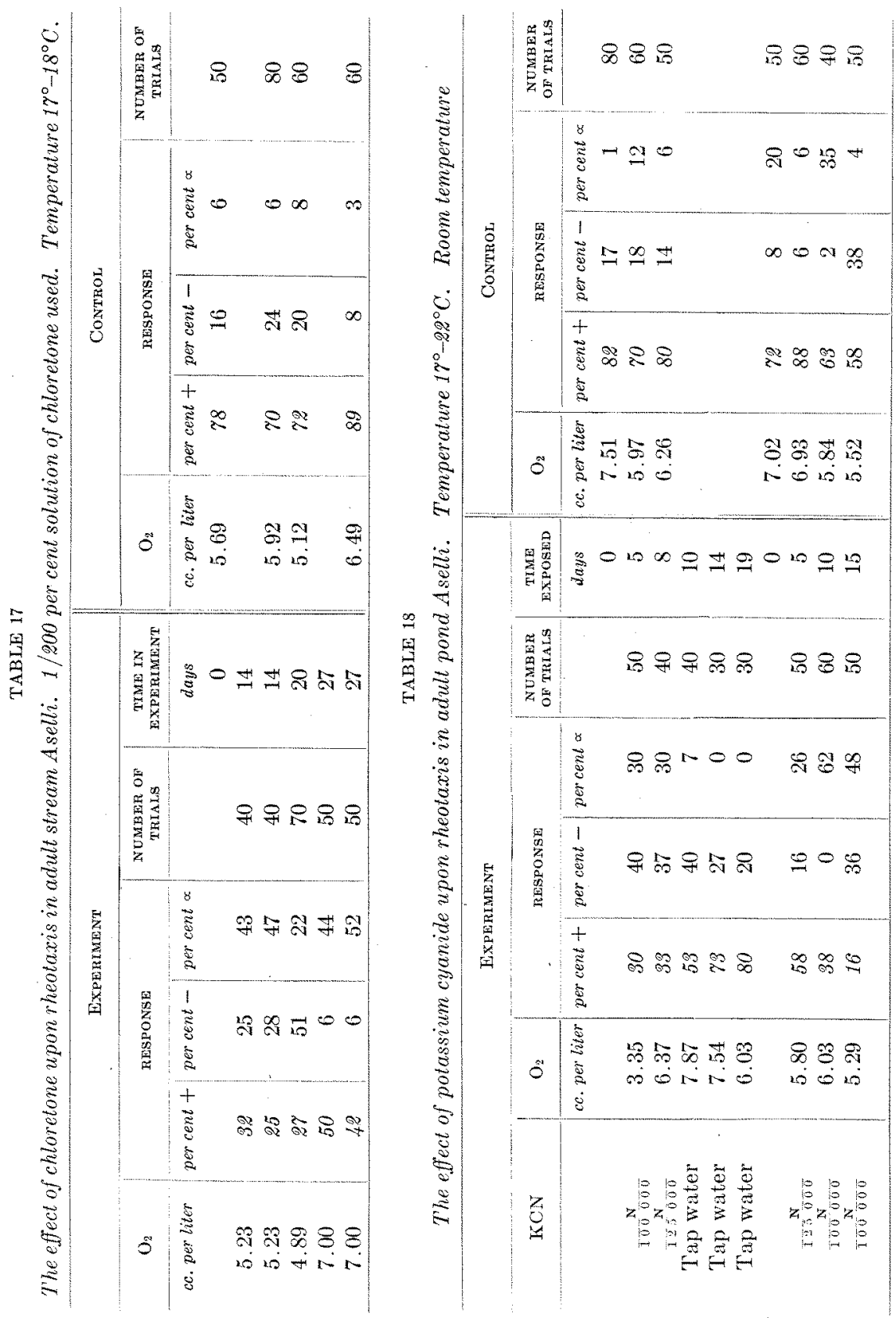


\section{e. Low temperature}

The general effect of lowering the temperature is to cause a decrease in the positiveness of the animals. This decrease is well shown in the experiments listed in table 19 . No attempt was made to find how small a decrease or how short an exposure would cause a reaction, the only care being to find if low temperature would affect the response.

The results show that a decrease in temperature does affect the rheotactic response in a marked manner, mainly in that it renders the isopods extremely inactive. Although these experiments do not show any acclimatization, yet by comparing with results listed in table 2 it will be evident that the isopods do come to give their normal positive response at as low as $4^{\circ} \mathrm{C}$. above zero. Again this is a reaction to a change of conditions. General experimental work has shown that a change in $3^{\circ}$ of temperature does not usually affect the reaction to current, although in one case a change of $4^{\circ}$ did have a marked effect. In

TABLE 19

The effect of low temperature upon rheotaxis in adult stream Aselli

I

\begin{tabular}{|c|c|c|c|c|c|c|}
\hline \multirow{2}{*}{$\begin{array}{l}\text { TEMPEK- } \\
\text { ATURE } \\
\text { C. }\end{array}$} & \multirow{2}{*}{$\frac{\mathrm{O}_{2}}{\text { cc. per liter }}$} & \multicolumn{3}{|c|}{ RESPONSE } & \multirow{3}{*}{$\begin{array}{c}\begin{array}{c}\text { NUMBER OF } \\
\text { TRIALS }\end{array} \\
50\end{array}$} & \multirow{2}{*}{$\begin{array}{l}\text { TIME EXPOSED TO } \\
\text { TEMPERATURE } \\
\text { GIVEN } \\
\end{array}$} \\
\hline & & per cenl + & per cent - & per cent $\propto$ & & \\
\hline 18 & 5.69 & 78 & 16 & 6 & & 7 days \\
\hline 5 & 8.41 & 16 & 84 & 0 & 50 & field test \\
\hline 18 & 4.99 & 94 & 4 & 2 & 50 & 2 days \\
\hline 4 & 6.08 & 42 & 16 & 42 & 50 & 12 hours \\
\hline 10 & 7.57 & 82 & 17 & 1 & 80 & 10 days \\
\hline \multicolumn{7}{|c|}{ II } \\
\hline 15 & 7.40 & 90 & 8 & 2 & 80 & over 10 days \\
\hline 0 & & 1 & 4 & 95 & 80 & $3 \frac{1}{2}$ hours \\
\hline 16 & 6.45 & 70 & 14 & 16 & 80 & $4 \frac{1}{2}$ hours \\
\hline \multicolumn{7}{|c|}{ III } \\
\hline 12 & 6.55 & 64 & 23 & 13 & 80 & over 10 days \\
\hline 0 & & 6 & 5 & 89 & 70 & 2 hours \\
\hline 12 & 6.50 & 66 & 20 & 14 & 70 & 5 hours \\
\hline
\end{tabular}


a temperature gradient, isopods collect at a temperature near that to which they have been previously exposed so that this optimum shifts with external conditions.

The effect of a decrease in temperature upon the bunching reaction has already been mentioned. Since the isopods become acclimated in both these cases, it was to be expected that they would show a similar reaction regarding the effect of temperature upon their rheotactic response.

\section{f. Starvation}

The effect of starvation is shown by the results tabulated in table 20. These experiments were carried on in filtered lake water. The only difference between the experiment and the control was that the latter contained a few leaves for food. The results show that as starvation progressed the positive responses of the isopods were diminished. The decrease shown in the control is due to the approach of the breeding season. As has been explained in other cases this may have helped cause the decrease in the experiment, but by comparison it will be apparent that the breeding season was not the major cause of the change in response.

\section{POND ASELLI}

\section{a. With increased oxygen}

(1) Normal adults. It is obvious that if the amount of oxygen present in the habitat is the determining factor in the rheotactic response of isopods, increasing the amount of oxygen present should increase the number of positive reactions. The amount of oxygen present was experimentally increased in three different ways: (1) The animals were placed in running tap water. This method is objectionable because it introduces a current, and. the mechanical effect of this might be the stimulating agent; (2) the aerating device already described was used; and (3) the isopods were placed in water containing a large amount of green water moss. Similar results were obtained from all three methods and these results are listed in table 21 . 


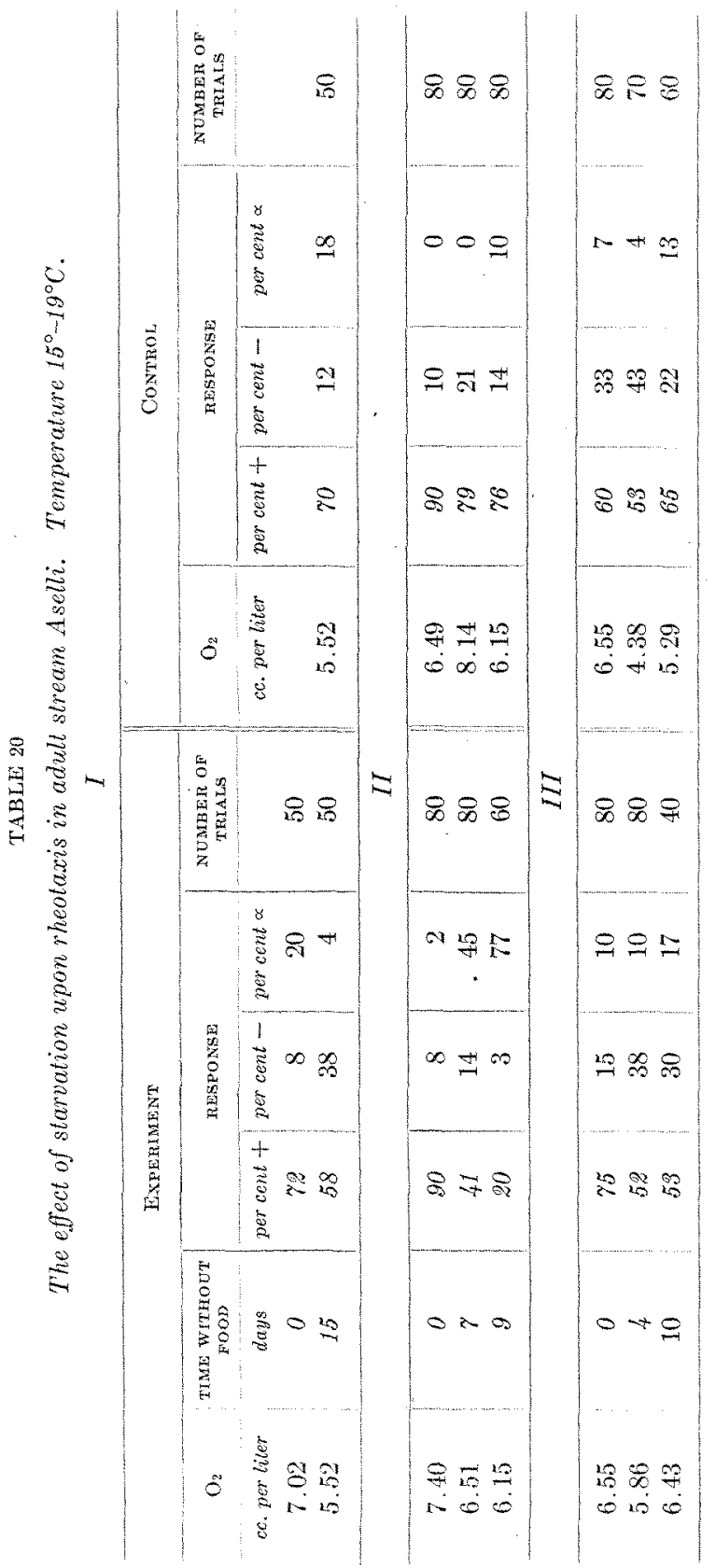


TABIEE 21

The effect of high oxygen upon rheotaxis in adult pond Aselli

\begin{tabular}{|c|c|c|c|c|c|c|}
\hline \multirow{2}{*}{$\frac{\mathrm{O}_{2}}{\text { cc. per liter }}$} & \multicolumn{3}{|c|}{ RESPONSE } & \multirow[t]{2}{*}{$\begin{array}{l}\text { NIANBER OF } \\
\text { TRIALS }\end{array}$} & \multirow{2}{*}{$\begin{array}{l}\text { TEMPERATURE } \\
. \quad \mathrm{C} .\end{array}$} & \multirow{2}{*}{$\begin{array}{c}\text { TIME IN HIGH } \\
\mathrm{O}_{2}\end{array}$} \\
\hline & per cent $t$ & per cent - & per cent $\propto$ & & & \\
\hline $5.12^{*}$ & 34 & 24 & 42 & 90 & 17 & 10 \\
\hline 5.12 & 40 & 31 & 29 & 35 & 17 & 11 \\
\hline 5.12 & 32 & 16 & 52 & 50 & 14.5 & 19 \\
\hline 5.12 & 46 & 10 & 44 & 50 & 14.5 & 19 \\
\hline 8.75 & 43 & 27 & 30 & 30 & 13 & 44 \\
\hline 9.31 & 20 & 28 & 52 & 50 & 11 & 54 \\
\hline 8.96 & 56 & 4 & 40 & 50 & 7.5 & 75 \\
\hline 8.96 & 44 & 6 & 50 & 40 & 7.5 & 73 \\
\hline 9.22 & 52 & 2 & 46 & 50 & 8.5 & 89 \\
\hline 5.86 & 50 & 50 & 0 & 10 & 10 & 188 \\
\hline 7.42 & 56 & 0 & 44 & 50 & 21.5 & 15 \\
\hline 4.84 & 70 & 0 & 30 & 20 & 17 & 65 \\
\hline
\end{tabular}

* The amount of oxygen present was at least $5.12 \mathrm{ec}$. per liter.

With the exception of the last two items, this table deals with one stock kept in a large aquarium in running water. The tests were made by selecting individuals at random and so give a fair representation of the reaction of the group. The increase in positive responses is not great but it is marked enough and constant enough to show that increasing the amount of oxygen present will affect the rheotactic reaction. One very significant fact is that there is no evidence of acclimatization in this or any subsequent test. The last two items show the same response with isopods kept in still water which gained its increased oxygen supply from the photosynthesis of Amblistigium moss.

If increasing the oxygen present in the water $5 \mathrm{cc}$. per liter caused an increase in the positive response, then increasing the concentration still more should cause a yet greater increase of the positive reaction. In order to test this, oxygen was bubbled through the aerating device previously described. The oxygen gave the following analysis; oxygen, 99 per cent, carbon dioxide trace, nitrogen 0.95 per cent. The results are listed in table 22 .

The increase in the oxygen caused a decided increase in the positive reactions as well as in the general activity. Where isopods in the control crawled slowly these ran rapidly, often 


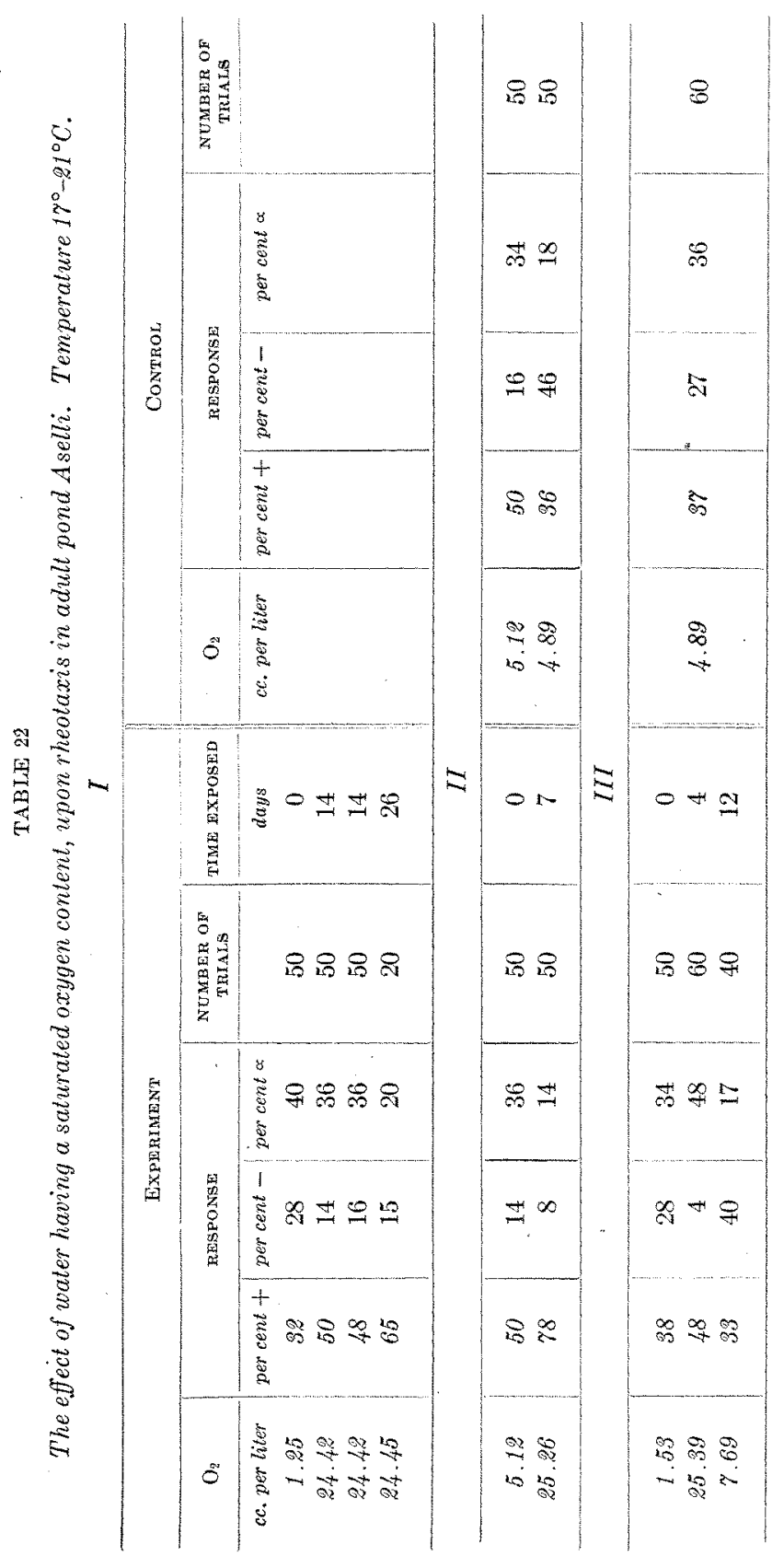


starting suddenly when no apparent stimulus was acting. Even when the rate of positive response was already high, as shown in the second part of the table, increasing the amount of oxygen present caused a large increase in the positive reaction. The third part of the table 22 shows the effect of allowing the oxygen in the water to escape gradually, and under these conditions the animals returned to a normal pond response while the amount of oxygen present was still much higher than that in their normal habitat. However it was very low in comparison with the amount of oxygen to which they had been previously exposed.

(2) Juvenile mores. Table 23 gives the effect of keeping juvenile pond Aselli in high oxygen for long periods of time. Other tests run for shorter times, give similar results but with less increase in positiveness. The right hand side of the table gives averages from the response during normal development and is placed here for comparison. Two things are brought out by the table. First, the pond isopods kept in a large amount of oxygen, develop not as normal pond mores but as stream Aselli, and second, that the time taken to acquire a given size is less when a larger amount of oxygen is present. The final results are especially interesting. At the age of 123 days the pond Aselli in high oxygen were $6 \mathrm{~mm}$. long and gave a 72 per cent response. It took those in low oxygen 193 days to attain the same size and then they gave only a 38 per cent positive response. There is no evidence of a return to the response normal for pond isopods.

(3) Response in straight current. Again the tests with the continuous straight current support the results with the discontinuous circular one. The results of these trials are summarized in table 24. Isopods from all three methods of furnishing increased oxygen were used with similar results, and one is forced to the conclusion that increasing the amount of oxygen present in the water makes juvenile pond Aselli give a positive rheotactic response comparable with that given normally by stream isopods. 
W. C. ALLEE
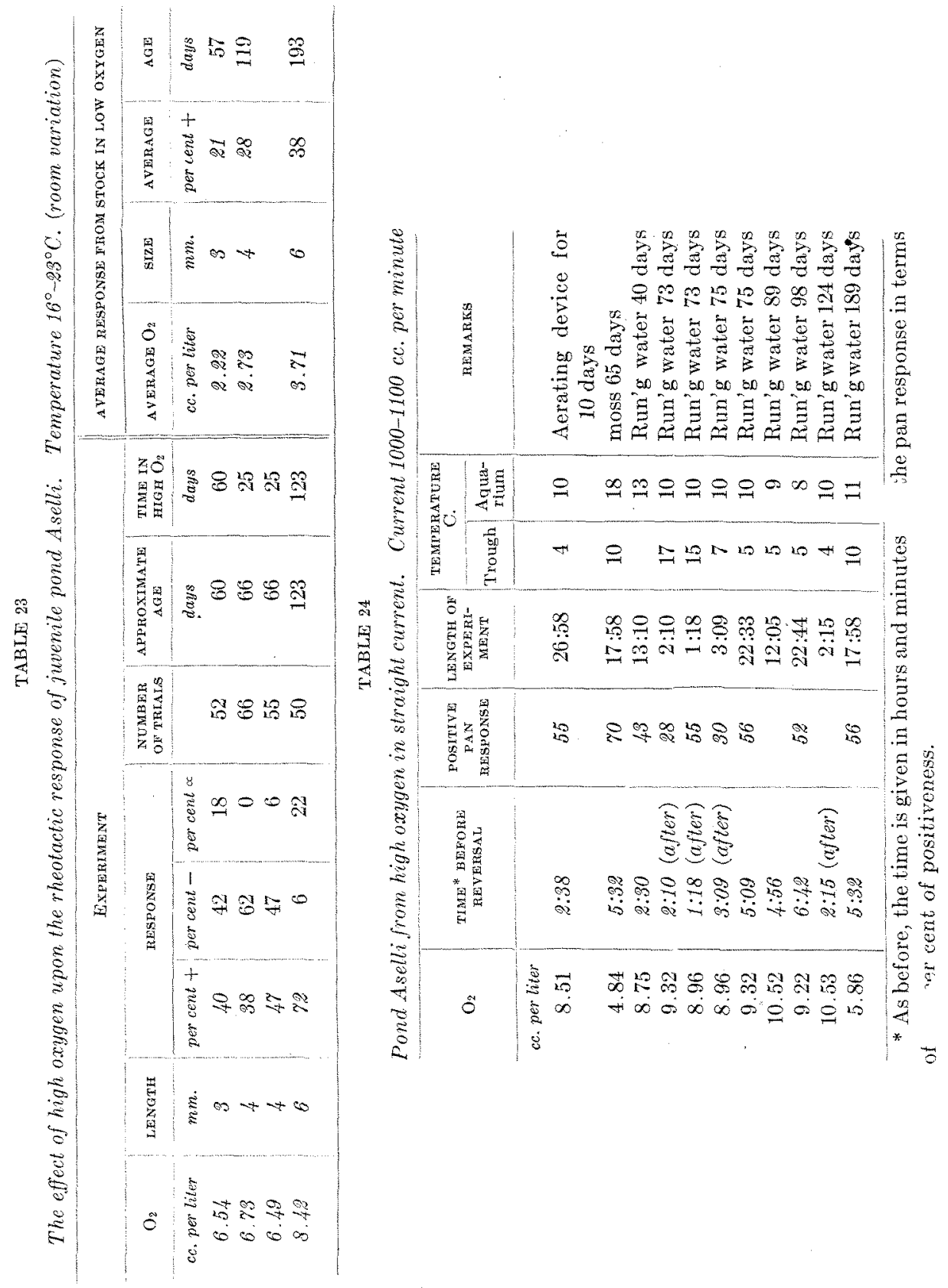


\section{b. Caffein}

Physiologically, caffein acts as a permanent stimulant. That is, there is no depressing after effect (Cushny, '10, p. 248). For this reason, experiments were run with pond isopods to find if such a stimulant would cause the same increase in the rheotactic reaction as that already produced by increasing the oxygen supply. For the experiments a solution of caffein in distilled water was made, saturated at room temperature, and this was added in small amounts to the ordinary tap water used in the experiments. The amount of caffein is shown in the table (25) in terms of cubic centimeters per liter of water.

The results of a number of trials are summarized in table 25 . The first part compares the effects of different strengths of caffein solution upon the rheotactic response. For the time used, 25 ce. of the saturated caffein solution per liter of water proved to be most stimulating although the mortality was high. Part 2 gives a series of trials with a group of pond Aselli exposed to $10 \mathrm{cc}$. of caffein solution per liter of water. The positive response was increased over 30 per cent and continued high for over eighty hours. The subsequent decrease in the positive response is due to the fact that the isopods apparently became acclimated to the caffein.

In the third part is given the record of another set of trials with $10 \mathrm{cc}$. of caffein solution per liter of water. Under these conditions, the isopods showed a slightly higher positive response and gave the same slump in positiveness at about the same time. These experiments were run at the same time as those given in part 2 and the same control was used. Part 4 shows the effect of increasing the caffein after the animals had gone back to their normal reactions, through becoming acclimated to the strength of caffein used. The increase given must be due to the increased amount of caffein, because no other factors were acting. After the acclimatization to this amount of caffein occurred, a further increase served to kill the animals rather than to increase their positive reaction. Again as in the case of the saturated oxygen, the isopods are decidedly more active in all their movements so 


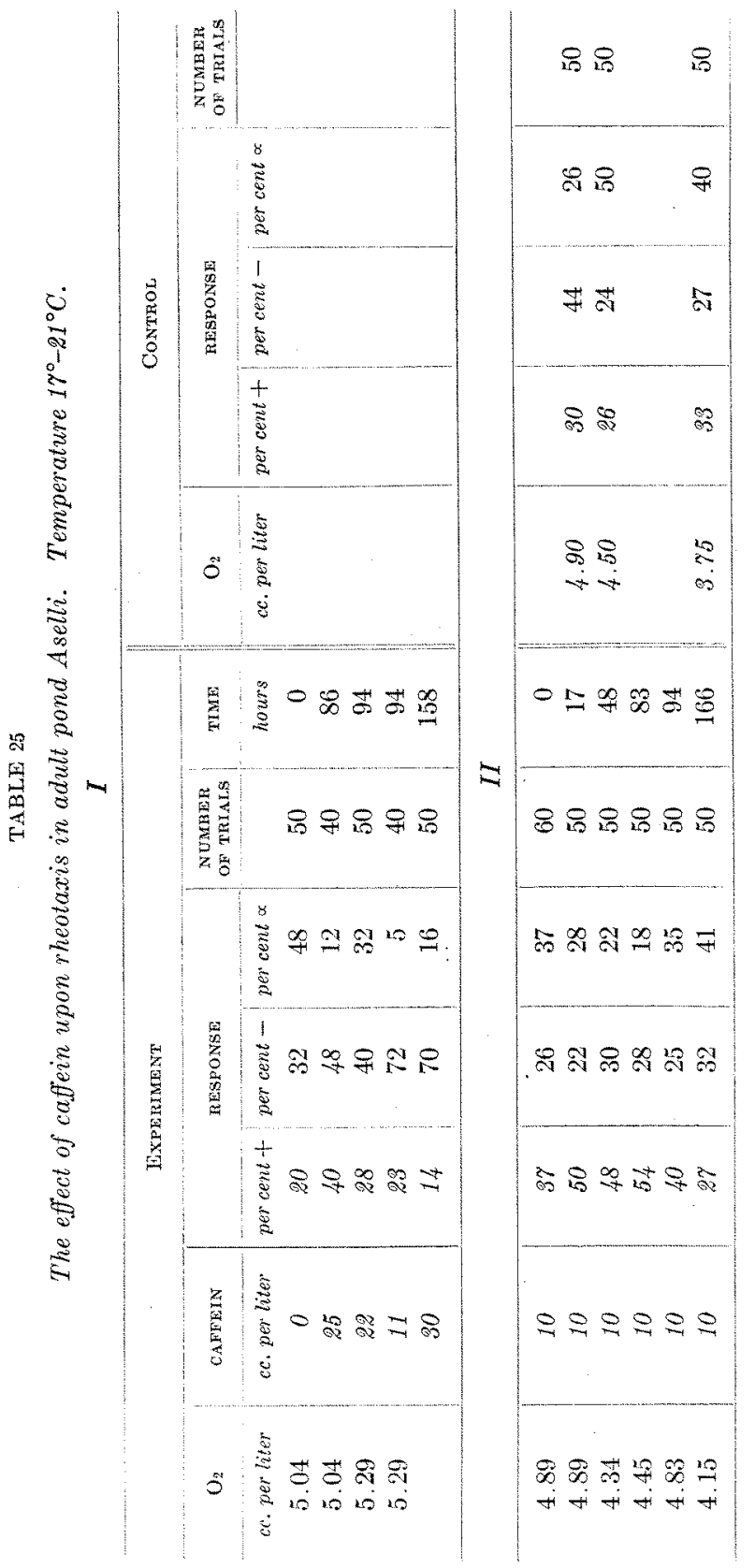




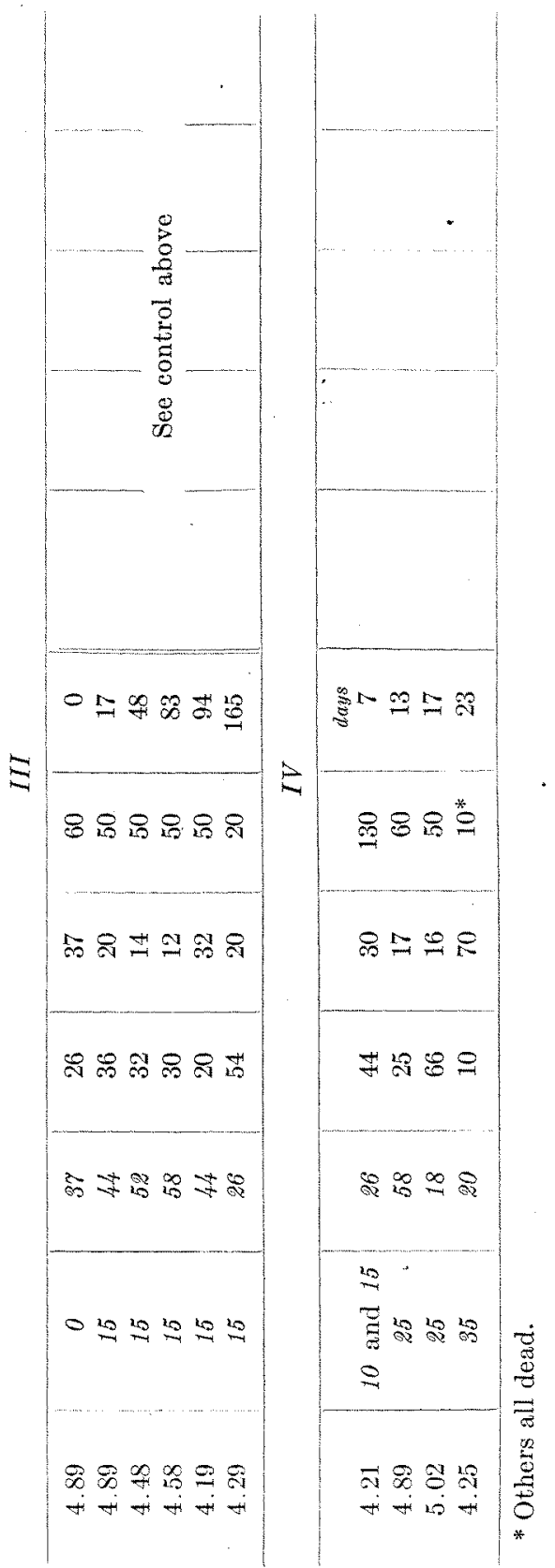


that their general activity as well as their rheotactic response is affected.

\section{c. Increase of temperature}

It was shown in a previous section that decreasing the temperature caused a lowering of the positive response; theoretically then an increase of temperature should show reversed results. The first experiment to test the effects of increased temperature was carried on by keeping the animals near a hot electric plate. The second, by keeping the animals in an automatically regulated heating tank. The results listed in the third part of table 26 were obtained by keeping the isopods in a melting ice pack exposed to a warm room temperature.

The first part of the table shows that the effects produced by an increase of $6^{\circ}$ operating for twelve hours, will persist for at least that much longer although the isopods are returned to the original temperature. The second set of trials indicates that the effect of continued high temperature is only temporary and the last three tests show that an increase of only $4^{\circ}$ may cause a most decided increase of positiveness. The last experiments were upon stream Aselli during the breeding season.

Other experiments show that a sudden increase of $10^{\circ}$ in temperature may cause either an increase or a decrease in the positive reaction, but if an increased response is still given after a $10^{\circ}$ raise in temperature, more heat always results in a diminution of the positive response. Whether a $10^{\circ}$ increase in temperature will cause an increase or decrease in the positivity, seems correlated with the general amount of activity of the isopods.

\section{EFFECT OF OXYGEN ON SIZE}

The relation between rate of growth and the ultimate size of the isopods, with the amount of oxygen present in the water has been mentioned already, yet this subject is of enough importance to merit a short general treatment. Colton ('08, pp. 410-447) demonstrated for snails, that the size may be correlated with the general oxygen supply, but the exact amount of oxygen present 
TABLE 26

The effect of raising the temperature upon rheotactic response I

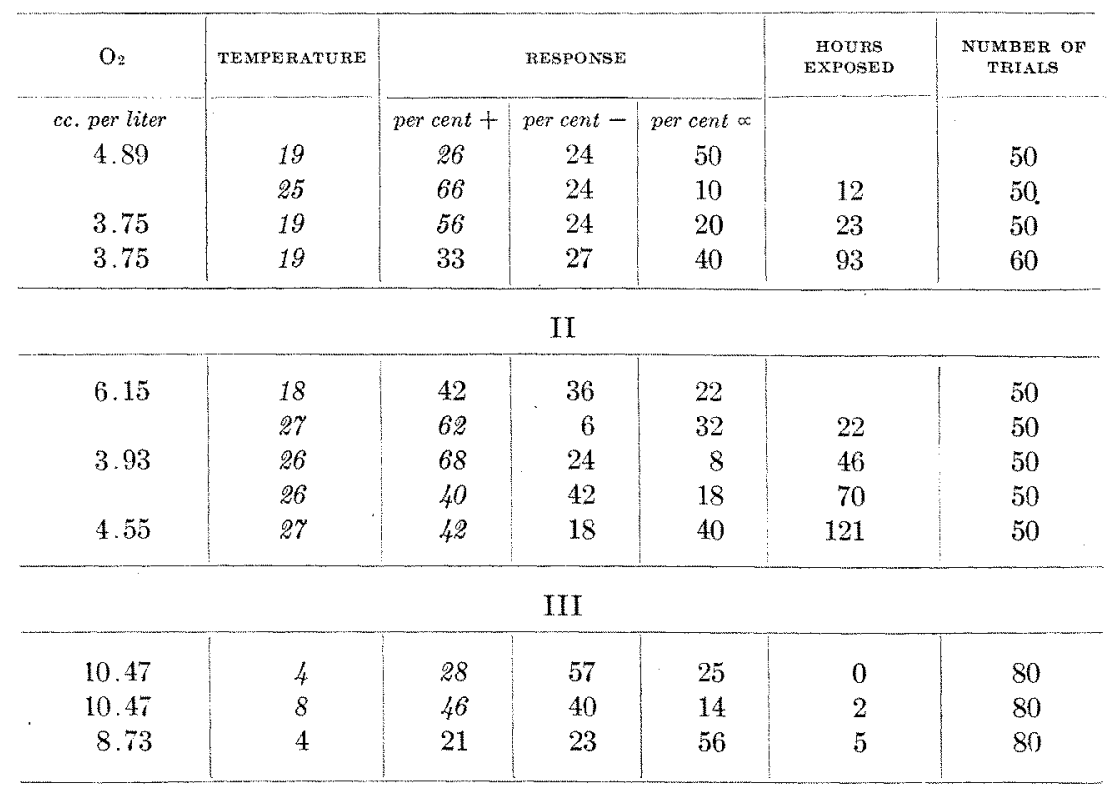

was not determined. It has already been stated that the stream isopods are on the average about $3 \mathrm{~mm}$. larger than those found in ponds. One set of twenty pond males averaged $12.75 \mathrm{~mm}$. in length; a set of twenty-eight pond females averaged $9.14 \mathrm{~mm}$. The average of twenty-five stream isopods of each sex gives the males a length of $15.3 \mathrm{~mm}$. and the females $12.2 \mathrm{~mm}$.

During the course of the experiments, the difference in size of isopods reared in low and high oxygen was quite noticeable and those with the higher amount of oxygen, other things being equal, were of a larger size. Although only a few of these were measured, the measurements were entirely characteristic of the general effect and are shown in table 27 , together with the average oxygen content and approximate age of the isopods measured.

Both sets of isopods were entirely comparable, being taken from the same stocks of animals. Both had plenty of food although perhaps the pond animals were better supplied. The 
stream isopods were all kept in still water, the higher amount of oxygen being supplied by means of the aerating device. In the pond isopods, however, those from the higher oxygen were kept in running water so that they were in a medium free from their waste products, which other workers have found to cause a diminution of size (Colton, l. c.). The results indicate that the amount of oxygen present is one of the factors and probably a major one in causing the size difference between pond and stream Aselli.

TABLE 27

\begin{tabular}{|c|c|}
\hline \multicolumn{2}{|c|}{$\begin{array}{l}\text { Effect of oxygen on size } \\
\text { Stream isopods }\end{array}$} \\
\hline Low $\mathrm{O}_{2}$ & $\mathrm{HI} \mathrm{O}_{2}$ \\
\hline 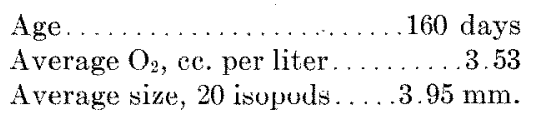 & $\begin{array}{l}\text { Age . . . . . . . . . . . . } 169 \text { days } \\
\text { Average } \mathrm{O}_{2} \text { cc. per liter . . . . . .6.02 } \\
\text { Average size, } 9 \text { isopods. . . } 5.89 \mathrm{~mm} .\end{array}$ \\
\hline \multicolumn{2}{|c|}{ Pond isopods } \\
\hline Low $\mathrm{O}_{2}$ & $\mathrm{HICH} \mathrm{O}_{2}$ \\
\hline 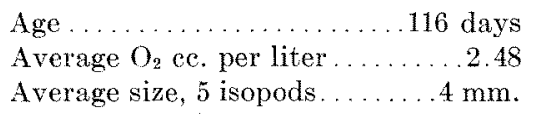 & 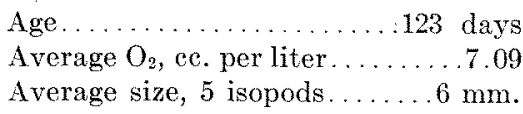 \\
\hline
\end{tabular}

\section{REACTIONS TO GRADIENTS OF GASES}

- Earlier experiments had shown that isopods would collect in their optimum light or temperature conditions if subjected to a series of graduated changes in either of these conditions. Since their rheotactic activity is more dependent on the oxygen supply than upon either light or temperature, experiments were tried to determine whether or not the Aselli would respond to gradients of oxygen and carbon dioxide.

These experiments were run in galvanized iron boxes especially designed for the purpose. Each box was $50 \times 30 \times 7.5 \mathrm{~cm}$. in dimensions. The bottom was covered with a layer of beeswax to give the isopods a better foothold for crawling. All the metal 
parts were painted dead black. Two centimeters from each end a screen of brass wire netting was placed in order to keep the isopods from the current introducers. These introducers were of brass tubing in the form of a capital $T$. An even distribution of the current across the pan was assured by having the cross bar of the $T$ punctured by eight equidistant holes, each $3 \mathrm{~mm}$. in diameter. The water was withdrawn by a brass tube $2 \mathrm{~cm}$. in diameter placed at the middle of the box with its lower side $4 \mathrm{~cm}$. from the waxed bottom. This was also drilled with equidistant holes, which were guarded by wire screening to prevent the isopods from escaping.

Tap water was introduced at one end and the boiled or the high carbon dioxide water, as the case might be, was allowed to flow in at the other. The most striking results were obtained with a flow of 200 to $400 \mathrm{cc}$. per minute at each end of the pan. This current spread over the $10 \mathrm{~cm}$. width of the pan, gave a flow of 5 to $10 \mathrm{cc}$. to each square centimeter of cross section, for each minute, and isopods do not react definitely to a flow of this strength.

With this device, a gradient of from $1.82 \mathrm{cc}$. of oxygen at one end of the pan to 8.14 cc. at the other, was obtained. For changes in salts see table 9 and discussion on p. 296. The half bound carbon dioxide was decreased $1 \mathrm{cc}$. per liter and the nitrogen content was lowered from 18 to 3 cc. per liter. In all cases a control was run in a box, the exact duplicate in every way of the experimental one. The only difference between the two sets of conditions was that in the control the same kind of water was introduced at both ends, the rate of flow being the same as in the experimental box. From five to ten isopods were used at a time and the experiments ran from one to six hours. Readings were taken at five, ten or fifteen minute intervals. In all cases the trials were made in very diffuse light or in total darkness. The readings were taken with a one candle power white light. The temperature was kept near enough that of the water from which the isopods were taken so that there was no temperature interference. 
Table 28 gives the summary from eight trials made with isopods from water having an oxygen content of over 5 cc. per liter. The grand totals show a decided positive response to the tap water end, although the control animals are almost equally distributed between the two ends. This mass result was confirmed by transferring the introducers and thus gradually changing the amount of oxygen present at either end, and also by stirring the isopods back to the center. In all cases the final reaction was in favor of the tap water end. Generally this reaction was the result of a series of movements about the box during which the isopods went from one end to the other but in a few cases there was a definite turning back when the boiled water was encountered.

Table 29 shows the response of isopods kept in an oxygen supply of leșs than $3 \mathrm{cc}$. per liter. Even under these conditions they did not collect in the boiled water end of the gradient in greater numbers than in the tap water end, yet the response to the tap water was cut from 77 to 53.3 per cent of the total number of readings taken. This probably means that having been kept in low oxy-

TABLE 28

Stream isopods from high oxygen in an oxygen gradient

\begin{tabular}{|c|c|c|c|c|c|c|c|}
\hline \multicolumn{5}{|c|}{ EXPERIMENT } & \multicolumn{3}{|c|}{ Control } \\
\hline & LOW & CENTER & EIGH & CURBENT: & Low & CENTER & Hran \\
\hline 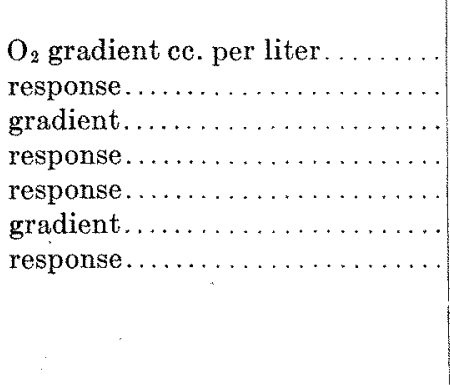 & $\mid \begin{array}{c}2.56 \\
15 \\
3.07 \\
6 \\
20 \\
1.82 \\
28 \\
87 \\
32 \\
9\end{array}$ & $\begin{array}{l}5.58 \\
5 \\
5.47 \\
2 \\
21 \\
\\
10 \\
22 \\
18 \\
4\end{array}$ & $\begin{array}{c}7.68 \\
40 \\
7.63 \\
122 \\
67 \\
8.14 \\
178 \\
388 \\
64 \\
73\end{array}$ & $\mid \begin{array}{c}\text { cc. per min. } \\
1200 \\
600 \\
\\
200\end{array}$ & $\begin{array}{c}20 \\
53 \\
53 \\
\text { no } \\
102 \\
160 \\
62 \\
37\end{array}$ & \begin{tabular}{|r|}
4 \\
9 \\
contro \\
39 \\
23 \\
35 \\
168
\end{tabular} & $\begin{array}{r}75 \\
169 \\
36 \\
45\end{array}$ \\
\hline Totals.. & 197 & 82 & 932 & & 434 & 278 & 410 \\
\hline Percentage of total trials...... & 16 & 7 & 77 & & 39 & 25 & 36 \\
\hline
\end{tabular}


TABLE 29

Stream isopods from low oxygen in an oxygen gradient

\begin{tabular}{|c|c|c|c|c|c|c|c|c|}
\hline \multicolumn{5}{|c|}{ EXPERIMENT } & \multicolumn{4}{|c|}{ Control } \\
\hline & Low & CENTER & HIGH & CURRENT: & Low & CENTER & HIG & $\begin{array}{c}\mathrm{O}_{2} \text { OF } \\
\text { CULTURE: }\end{array}$ \\
\hline $\mathrm{O}_{2}$ gradient ce. per liter & 3.07 & 5.47 & 7.63 & ce. per $\min$ & & & & co. per liter \\
\hline $\begin{array}{l}\text { response } \ldots \ldots \ldots \ldots \ldots \\
\text { gradient } \ldots \ldots \ldots \ldots \ldots\end{array}$ & $\begin{array}{c}23 \\
1.82\end{array}$ & 18 & $\begin{array}{l}40 \\
8.14\end{array}$ & 600 & 5 & 3 & 26 & 2.44 \\
\hline response....... & 26 & 9 & 151 & 400 & 41 & 6 & 139 & 2.12 \\
\hline & 95 & 43 & 286 & 525 & 189 & 38 & 197 & 2.22 \\
\hline & 80 & 26 & 71 & 525 & 65 & 43 & 82 & 2.56 \\
\hline & 22 & 9 & 26 & 300 & 25 & 19 & 22 & 3.00 \\
\hline & 42 & 38 & 96 & 300 & 39 & 86 & 51 & 2.00 \\
\hline gradient. & 3.24 & & 11.00 & & & & & \\
\hline response...... & 79 & 12 & 61 & 300 & 67 & 11 & 74 & 0.3 \\
\hline & 17 & 30 & 28 & 300 & 77 & 11 & 14 & 2.44 \\
\hline Totals.. & 384 & 185 & 759 & & 508 & 217 & 605 & \\
\hline $\begin{array}{c}\text { Percentage of total } \\
\text { trials............. }\end{array}$ & 29 & 14 & 57 & & 38 & 17 & 45 & \\
\hline
\end{tabular}

\section{TABLE 30}

Stream isopods in a carbon dioxide gradient From water having less than $2 \mathrm{cc}$. per liter current $300 \mathrm{cc}$. per min.

\begin{tabular}{|c|c|c|c|c|c|c|}
\hline \multicolumn{4}{|c|}{ Experiment } & \multicolumn{3}{|c|}{ Controt } \\
\hline & HIGH & CENTERR & Low & HIGH & CENTER & Low \\
\hline $\mathrm{CO}_{2}$ gradient cc.perliter & 24 & & 3.5 & & & \\
\hline response ............ & 25 & 7 & 45 & 30 & 3 & 44 \\
\hline gradient............ & 45 & & 3 & & & \\
\hline response ......... & 28 & 2 & 40 & 17 & 29 & 34 \\
\hline gradient.......... & 59 & & 3 & & & \\
\hline response ......... & 20 & 3 & 37 & 36 & 8 & 16 \\
\hline gradient.......... & 60 & & 7 & & & \\
\hline response ......... & 7 & 0 & 36 & 23 & 4 & 15 \\
\hline gradient......... & 80 & & 20 & & & \\
\hline response..... & 19 & 0 & 59 & 52 & 9 & 17 \\
\hline gradient..... & 551 & & 138 & & & \\
\hline response....... & 5 & 0 & 72 & 38 & 6 & 40 \\
\hline Totals......... & 104 & 12 & 289 & 196 & 59 & 166 \\
\hline $\begin{array}{l}\text { Per cent of total num- } \\
\text { ber of trials.......... }\end{array}$ & 26 & 3 & 71 & 47 & 14 & 39 \\
\hline
\end{tabular}


gen conditions, the isopods became more tolerant of low oxygen, although their optimum amount of oxygen was still higher than that furnished by the low end of the gradient.

The results with a carbon dioxide gradient are given in table 30. These trials show that stream isopods avoided an amount of carbon dioxide equivalent to the highest quantity found in nature, but that the avoiding is much more pronounced as the amount of carbon dioxide is increased. The result is, that although the higher amount of carbon dioxide diffuses against the current to the low end of the gradient, the isopods collect in an amount of carbon dioxide to which they are strongly negative when such a response is possible.

These gradient experiments show that the stream isopods tend to collect in the amount of oxygen or carbon dioxide to which they are accustomed. In nature this reaction would tend to keep the stream isopods from collecting in conditions that might affect their general state of metabolism, and in this way affect their power of resistance to the stream current.

\section{SUMMARY OF EXPERIMENTAL RESULTS}

The major experiments may best be classified on the basis of the result, of the materials used, upon the rheotactic response. Under this division they fall naturally into two groups; those that decrease and those that increase the positiveness of the rheotactic response. These may be summarized as follows:

A. Conditions that decrease the positive rheotactic response:

1. Low oxygen

2. Chloretone

3. Potassium cyanide

4. Low temperature

5. Sudden extreme increase of temperature

6. Carbon dioxide.

7. Starvation

To these may be added the life history effects as shown in the breeding season and the juvenile reactions. 
B. Conditions that increase the positive rheotactic response:

1. Atmospheric saturation of oxygen

2. Complete saturation of oxygen

3. Caffein

4. Increase of temperature, if not too extreme

The rheotactic responses given by the isopods under different conditions are summarized in the following series of curves. These graphs are based upon all the experimental data at hand, and plot only the positive responses of the isopods. They necessarily show only two factors, namely, time and the per cent of

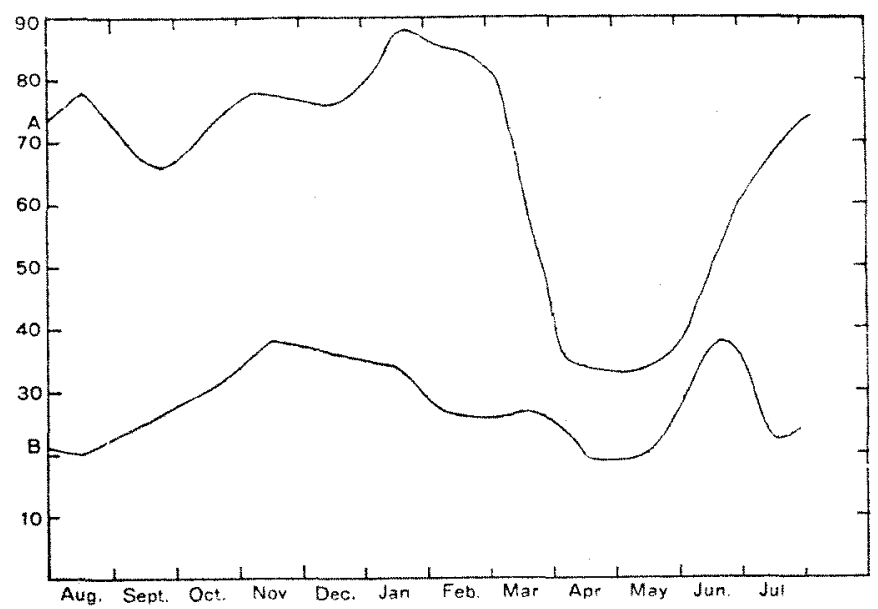

Fig. 5 Normal rheotactic response. A, Adult stream; $B$, Adult pond isopods

positive responses. The former is given by the abscissae and the latter by the ordinates. The other accessory data may be found by referring to the different tables.

Figure 5 shows the curve for the normal rheotactic response for adult stream $(A)$ and pond $(B)$ isopods. The general sim larity of the two curves is noteworthy. The most striking difference, aside from the lower positive response of the isopods, is the different degree in which the breeding season affects the two mores. 
The unbroken line $(A)$ in figure 6 gives the effect of a decreased oxygen supply upon adult stream Aselli. The response consists of four periods. First there is the lessening of the positive response which is followed by partial acclimatization. This is followed by the breeding season after which the isopods are either more vigorous or else are more capable of becoming acclimated than before and so give a stronger positive response. The broken lines $(B)$ show the effect produced by keeping the pond Aselli in tap water, the steeper curve being plotted for younger animals. In neither case is there any sign of acclimatization.

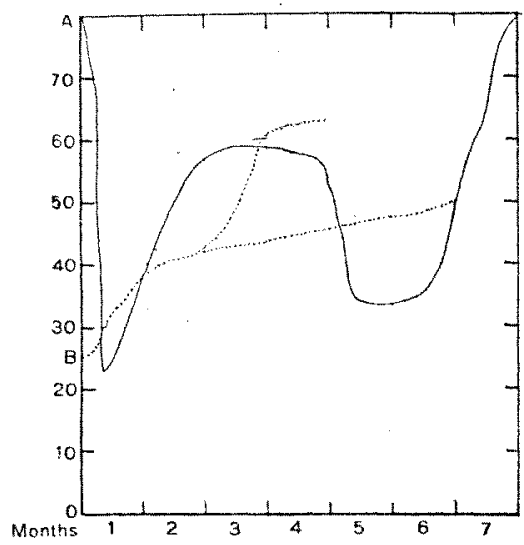

Fig. 6 Adult isopods in reversed oxygen supply. $A$, Adult stream; $B$, Adult pond isopods.

The broken line $(B)$ in figure 7 gives the results produced by a low oxygen supply, upon the rheotactic response during the breeding season. In general there is first an increase of the positive response, followed by a decided reversal. The unbroken line $(A)$ shows the effect of an increased carbon dioxide supply The effect of the decreased oxygen is probably due to its action first, upon the germinal glands, causing a cessation of their activity, which gives more energy for other activities. This is followed by the direct depressing effect of the low oxygen upon the tissues themselves. The results so far obtained with carbon dioxide may be explained by its general narcotic action. 
The solid lines in figure 8 give the effect of low $\left(S_{2}\right)$ and high $\left(S_{1}\right)$ oxygen content upon the rheotactic reaction of juvenilestream Aselli. The rheotactic reactions are too indefinite during the first month to be considered. The second month shows the same state of development in each environment but from that time on the responses are entirely different. It is especially noteworthy that the isopods kept in a low supply of oxygen throughout their lives, did not become strongly positive even after the breeding season, which came in their fifth month. That is, they did not show the same capacity for regulating, given by adults under the same conditions. The broken lines give the reactions of isopod

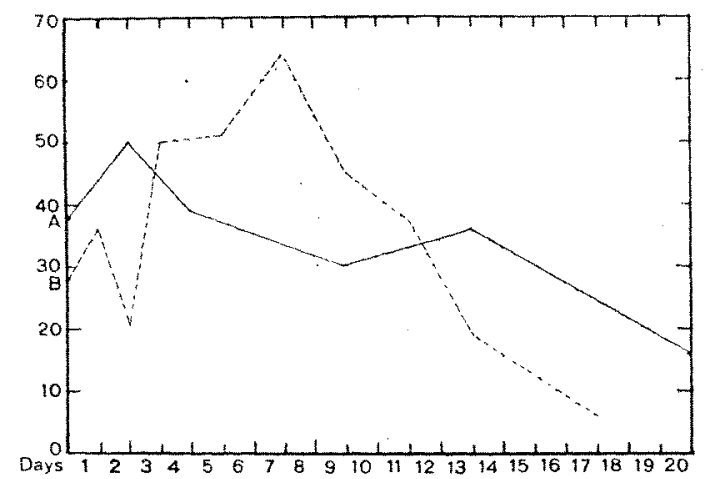

Fig. 7 The effect of increased carbon dioxide and decreased oxygen upon the rheotactic reaction during the breeding season. $A$, carbon dioxide; $B$, oxygen.

of pond parentage $\left(P_{1}\right)$ in high, $\left(P_{2}\right)$ in low oxygen supply, and it is evident that their rheotactic reactions do not depend on their ancestry but on their environment.

Figure 9 compares the results of different depressing agents at the concentrations used. Apparently a rapid decrease in temperature $(A)$ is most effective and most transitory. Carbon dioxide $(C)$ from 200 to $300 \mathrm{cc}$. per liter seems to be second in both these qualities. The isopods become slowly acclimated to chloretone $(B)$ at the strength used, but show no such tendency with the potassium cyanide $(D)$ in the concentration used. Starvation $(E)$ also acts as a continued depressant. 


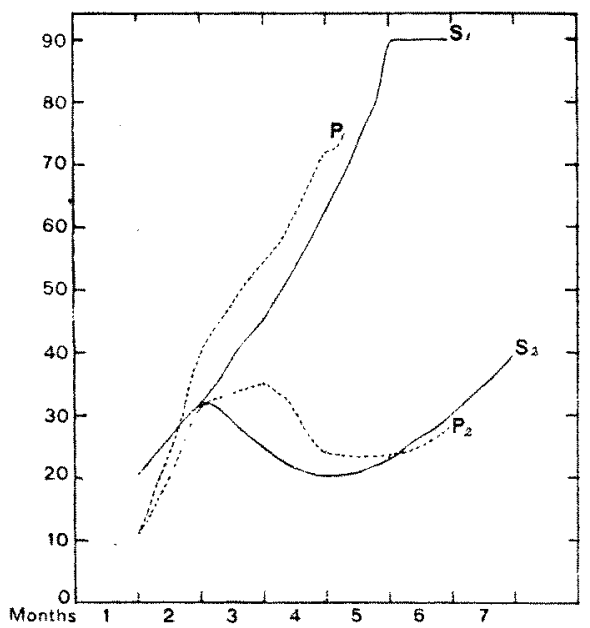

Fig. 8 Rheotaxis during isopod development in different amounts of oxygen. $S_{1}$, Stream isopods in high oxygen, $S_{2}$, in low oxygen; $P_{1}$, pond isopods in high oxygen, $P_{2}$, in low oxygen.

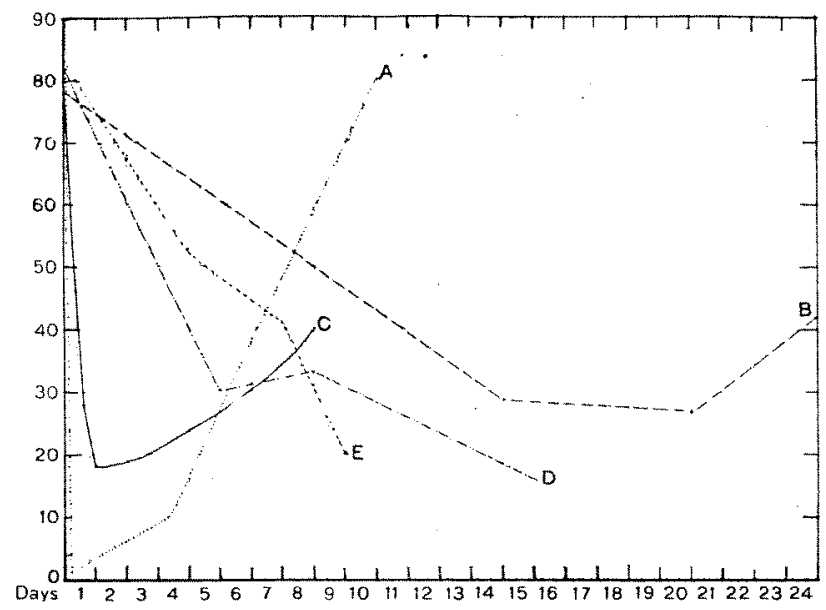

Fig. 9 The effect of depressing agents upon rheotaxis. A, low temperature; $B$, chloretone $1 / 200$ per cent solution; $C$, carbon dioxide, $200-300$ ce. per liter; $D, \mathrm{KCN}, \mathrm{n} / 100,000 ; E$, Starvation. 
Figure 10 gives the curve for the effects produced by stimulating agents. Two distinct results were obtained with water saturated with oxygen $(B, D)$. In one case $(B)$ the isopods were already giving an increased positive response due to the relatively high oxygen content of the water. In both cases, however, the increased positiveness was maintained until death resulted. The isopods, however, become acclimated to both a higher temperature $(A)$ and to a supply of caffein $(C)$. When once acclimated to

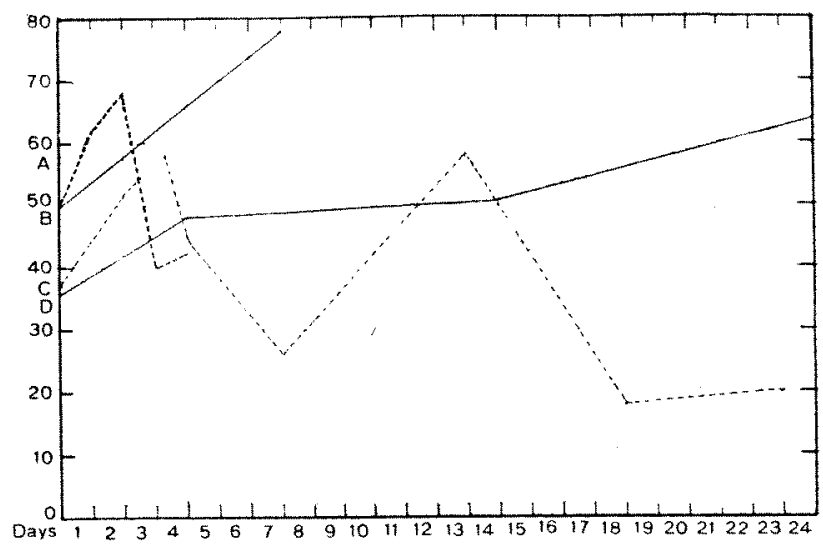

Fig. 10 The effect of stimulating agents upon rheotaxis. $A$, Inereased temperature, about ten degrees; $B, D$, saturated oxygen, 25 cc. per liter; $C$, caffein, 10-25 ce. saturated solution per liter.

the latter, a further inerease up to the point of toxicity caused increases in the positive response.

The experiments have also shown that the size of the isopods and their rate of growth are correlated with the oxygen supply. Also that when subjected to a gradient of different concentrations of oxygen or carbon dioxide, Aselli will collect in the concentration nearest that to which they are accustomed. 


\section{DISCUSSION}

In presenting these results the writer realizes fully the attending imperfections and the need of more work along some lines. But in order to do further work with this material, in this field, in an intelligent manner, these general relationships had to be first blocked out. It is the author's intention to follow this paper with a study of the effect of the same conditions upon another characteristic isopod reaction, and to further analyze the interesting relations shown during the breeding season.

The principles upon which this paper is based have been successfully worked out (under the author's direction) with amphipods by Mr. W. J. Saunders in an unpublished master's thesis and with amphipods and planarians by graduate students doing course work in experimental animal behavior. The work of these students has shown that the rheotactic reactions of both amphipods and planarians are comparable with those of pond and stream isopods and may be controlled by the same external factors.

In the summary of the experimental results just given, the basis for classification was made the positiveness of the isopods in their rheotactic responses, but if the heading were rather the effect of these conditions upon the metabolic state of the organism, the summary would not need to be changed. For all the conditions that have been found to cause a decrease in the positive reaction are known to depress the rate of animal metabolism (Child, l.c., p. 173). Low oxygen (Haldane and Smith, '97, p. 242) potassium cyanide (Geppert, '99, p. 208) and high carbon dioxide (Cushny' '10, p. 587) do this by directly decreasing the oxidations. Chlo etone belongs to the general group of anaesthetics that are known to have a depressing effect upon certain of the fundamental meta-bolic reactions (Child, l.c., p. 173; Cushny, l.c., p. 195). The decrease in activity due to low temperature is a well known phenomenon in both animals and plants, as is also the depressing effect of an increase of temperature above the optimum for life relations, while starvation decreases metabolism by removing the material to be oxidized and so gives the same results from the other side of the equation. On the other hand, the rate of metab- 
olism increases with the increase of the oxygen dissolved in water (Lingle '02, p. 83; Martin, '06, p. 303; Loeb, '06, p. 95). Then, too, Piéron ('08, pp. 1020 and 1061) measured the amount of oxygen present at different times in sea water and found that Actinians expand and retract their tentacles as the oxygen tension of the water increases and decreases. These observations were confirmed by experiments in aquaria, but Bohn ('08, p. 1163) questions Piéron's interpretation of his results and attributes these rhythms to much more complex factors. An increase in temperature increases metabolism providing, of course, the increase is not too rapid or too great. Caffein is known to have a permanent stimulating effect (Cushny, l.c., p. 248).

From this evidence, the rheotactic reaction in isopods must depend upon the metabolic state of the animals. All the observed facts concerning their response in nature support this view, except that in young animals the rate of metabolic reaction is higher than in the older ones. Yet the juvenile isopods give either no rheotactic reaction or are very indifferent to the current. But with these young isopods, conditions that favor a high metabolic rate cause positive reactions to appear sooner and to be a great deal stronger than in those animals kept in conditions that depress metabolism. Then, too, the clinging reaction is strong in these young isopods and even under the most favorable conditions, they do not move about rapidly. Since the positive rheotactic response seems correlated with the degree of motile activity of the isopods, this tendency to cling in one place would account for the apparent discrepancy in the lack of positiveness in these juvenile Aselli.

In nature the complex of conditions found in ponds furnishes isopods that give a low positive rheotactic response, while stream conditions produce the opposite result. The amount of oxygen in these two habitats varies greatly, as has already been pointed out, and this variation appears sufficient to account in a large measure for the difference in the reactions. Of course the fact that the pond water usually contains more organic waste products than are found in the streams, may help to cause the difference in the reactions. But this does not seem to be the important 
factor since pond isopods kept in well aerated water containing a large amount of waste products gave the same increase in the positive reaction, as when running tap water was used. Also the cause of difference in response in isopods from the two habitats cannot be due to the mechanical stimulation of the current for experiments with both stocks show that this cannot be true. Pond Aselli kept in still water but in high oxygen, increase in positiveness, while stream Aselli under the same conditions maintain their high percentage of positive responses. The isopods which gave the reactions in table 1 had been in still water all their life and yet gave a positive response of over 89 per cent. From these considerations it appears that oxygen is either the most important environmental factor in determining the rheotactic response or it is the best single factor index of the effect of the complete environment upon this reaction.

Through the tables one can see evidences of irregularity in the response of the isopods from the same conditions. This irregularity was due to two causes. First, the error of the method, which has been shown to be about 5 per cent. This error is due, in part, to the tendency of the isopods to keep on going in the way they may be headed. This would account for an isopod going positive nine times and negative the tenth. The second cause of the irregularity is the fact that an 80 per cent positive response on the part of five isopods may mean that four of them went positive every time while the fifth was entirely negative. At first sight this would appear to be a serious objection to the plan of selecting the animals to be tested at random from the stock under consideration. Conceivably one might pick five isopods that would all give a response opposite to that of the general culture. In practice however this has not occurred and the large number of trials is a sufficient safeguard against such a source of error. However in the later experiments every animal used, both in the control and in the experiment, was tested and more uniform results were obtained in this way.

The question at once arises as to why one member of the stock under the same external conditions as the others should give a different rheotactic response. One of the reasons is the state of 
the isopod, regarding the time distance from the moulting period. The exact bearing of the moulting cycle upon rheotaxis has not yet been worked out, but evidence is accumulating to show that in stream isopods, the moulting period and the time immediately following it are characterized by an indefinite or at any rate a weak rheotactic response.

Regarding the permanence of the modifications produced, it has been repeatedly mentioned, that in pond isopods kept in high oxygen, there was no reversal to the normal pond response, although in two cases these experiments ran for over six months. On the other hand, the stream isopods seemed to possess a power of acclimatization, and a return to the normal stream positiveness in a fairly low oxygen content. However, in the case of the isopods reared entirely in low oxygen, this increase in positiveness was much less marked. Apparently if the stock could have been carried through a few more generations the response would have been entirely that of pond isopods. Hence it would appear that the reactions, with which this paper is dealing, are distinctly dependent upon the environment for their continuance. On the other hand the taxonomic differences, as the number of spines on the propodus of the first thoracic appendage, show the same variation in both habitats. That is, the taxonomic differences are inheritable characteristics of the species, and are not dependent upon external conditions, while the behavior characters here studied are almost independent of heredity.

The size of the isopods has been shown to be correlated with the amount of oxygen in the water and size is often used in defining taxonomic species. So here we have one structural element that does depend directly upon the environment. This bears out the statement of Shelford ('11 a, p. 593) that animal behavior is usually plastic while animal structure is only slightly plastic. Since aside from the size, the taxonomic characters of isopods from the two habitats are the same, the animals cannot be referred to as a stream 'form' as contrasted with a pond 'form,' because in its general usage form is applied to a morphological entity. However, the term 'mores' as used in general in the Concilium Bibliographicum, and as specifically defined by Shelford (11, p. 30). 
does exactly express the difference between the pond and stream isopods. Thus we are dealing with the pond mores and the stream mores of Asellus communis, which depend on environmental rather than on hereditary differences for their distinctive features.

In the isopods used, these two mores occur in the same taxonomic species, but in the amphipods, Mr. Saunders (1.c.) found a different species in the ponds from that in the streams. This means that with the amphipods studied the natural mores would run parallel with the taxonomic species. But the pond mores could be transferred directly into stream mores without affecting their structural characters. Thus the mores or 'ecological species' are independent of taxonomic species, and a single ecological species may be composed of half a dozen taxonomic species or of only a fraction of one.

The general conclusion to be drawn from this series of experiments is that in the isopod, Asellus communis, the rheotactic reaction is dependent upon the metabolic state of the animal for its degree of positiveness and that the natural or experimental conditions which affect the metabolic state of the animal, change its rheotactic response. That is to say, the rheotactic reaction is here an expression of the metabolic condition (physiological state) of the isopod and may be controlled by those factors known to control animal metabolism.

It is a pleasure to acknowledge my indebtedness to Dr. C. M. Child for his many helpful criticisms but my best thanks are due to Dr. V. E. Shelford, who first suggested this problem and under whose direction the work has been done.

\section{BIBLIOGRAPHY}

Allee, W. C. 1911 Seasonal succession in old forest ponds. Trans. Ill. Acad. Sci., vol. 4, pp. 126-131.

Allen, G. D. 1910 Rheotaxis of Planaria dorotocephala. Unpub. Master's Thesis; Library of Univ. of Chicago.

Banta, A. M. 1910 A comparison of the reactions of a species of surface isopod with those of a subterranean species. Jour. Exp. Zoöl; vol. 8, pp. 243$310 ; 439-488$. 
Brrge, E. A. ANd JUday, C. 1911 The internal lakes of Wisconsin. Wis. Geol. and Nat. Hist. Surv.; Bull. 22, 259 pp.

Boнn, G. 1903 De l'évolution des connaissances chez les animaux marins littoraux. Bull. Inst. Gén. Physiol.; no. 6, 67 pp.

1903 a Les Convoluta roscoffensis et la thérie des causes actuelles. Bull. d. Hist. Nat., pp. 352-64.

1905 Attractions et oseillations des animaux marins sous l'influence de la lumière. Inst. Gén. Psychol., Memoires I. 110 pp.

1908 Les facteurs de la rétraction et de l'épanouissement des Actinies. Comp. Rend d. Séances, Soc. d. Biol., Paris, vol. 44, pp. 1163-6.

CHud, C. M. 1910 Analysis of form regulation with the aid of anaesthetics. Biol. Bull., vol. 18, pp. 161-173.

1912 Dynamics of morphogenesis and inheritance in experimental reproduction. Jour. Exp. Zoöl., vol. 13, pp. 103-152.

Colton, H. S. 1908 Some effects of environment on growth of Lymnaea columella, Say. Proc. Ac. Nat. Sc., Philadelphia, pp. 410-47.

Cushny, A. R. 1910 Pharmacology and therapeutics, 10th edition. $744 \mathrm{pp}$. Philadelphia.

Gamble, F. W. and Keeble, F. 1903 The bionomics of convoluta roseoffensis with special reference to its green cells. Qr. Jour. Micr. Sci., vol. 47, pp. 363-431.

GepPent, J. 1899 Über das Wesen der Blausäurevergiftung. Zeitschr. klin. Med, vol. 15, pp. 208-307.

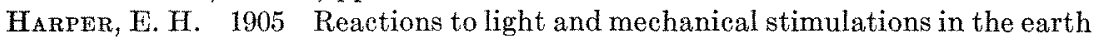
worm, Perichaeta bermudensis (Beddard). Biol. Bull., vol. 10, pp. 17-34.

Haldane, J. ANd Smith, L. J. 1897. The absorption of oxygen by the lunge. Jour. of Physiol., vol. 22, pp. 331-59.

Holmes, S. J. 1903 Sex recognition among Amphipods. Biol. Bull., vol 5, pp. 289-292.

1905 The selection of random movements as a factor in phototaxis. Jour. Comp. Neur., vol. 15, pp. 98-112.

JENnings, H. S. $1904 \mathrm{~b}$ Reactions to stimuli in certain Rotifera. Carnegie Inst. of Wash., Publ. 16, pp. 73-88.

$1904 \mathrm{~d}$ Physiological states as determining factors in the behavior of lower organisms; ibid., pp. 109-127.

1906 Behavior of the lower organisms. $366 \mathrm{pp}$. New York.

Lingle, D. J. 1902 The importance of sodium chloride in heart activity. Am. Jour. Physiol., vol. 8, pp. 75-99.

LoEB, J. 1906 Utber die Ursachen der Giftigkeit einer reinen Chlornatriumlösung und ihrer Entgiftung durch $\mathrm{K}$ und Ca. Biochem. Zeitschr., vol. 2, pp. 81-111.

MARTin, E. G. 1906 A study of the absorption and consumption of oxygen in heart tissue. Am. Jour. Physiol., vol. 15, pp. 303-320.

Moebius, K. 1873 Die Bewegung der Thiere und ihr psychischer Horizont. 20 pp. Kiel.

Mast, S. O. 1903 Reactions to temperature changes in Spirillum, hydra, and fresh-water Planarians. Am. Jour. Physiol., vol. 10, pp. 165-190. 1911 Light and the behavior of organisms. $410 \mathrm{pp}$. New York. 
PEARL, R. 1903 The movements and reactions of fresh-water Planarians. A study in animal behavior. Qr. Jour. Micr. Sei., vol. 46, pp. 509-714.

Préron, H. 1908 De l'influence l'oxygène dissous sur le comportment des invertebrés marins. Comp. Rend. de Séances., Soc., d. Biol., Paris, vol. 44, pp. $886-8 ; 955-7 ; 1020-2 ; 1061-3 ; 1161-2$.

Prexkr, W. 1886 Uber die Bewegung der Seesterne. Mith. a. d. zool. Stat. z. Neapel, vol. 7, pp. 27-127; 191-233.

Report of committee on standard methods of water analysis to the Lab. Sect. of The Am. Health Ass. 1905. Jour. Inf. Diseases. Supplement, no. 1, pp. 1-141.

Rtchardson, Harrimt 1905 Monograph on the isopods of North America. Bull. U. S. Nat. Mus., no. 54, 727 pp.

Romanes, G. J. 1885 Jellyfish, starfish and sea urchins. 323 pp. New York.

SAUNDERS, W. J. 1911 A study of behavior of amphipods with notes on their life histories. Unpub. Master's Thesis; Library of Univ. of Chicago.

Shelford, V. E. 1911 Ecological succession. I. Stream fishes and the method of physiographie analysis. Biol. Bull., vol. 21 pp. 9 36.

1911a Ecological succession. II. Pond fishes. Biol. Bull., vol, 21, pp. 127-151.

$1911 \mathrm{~b}$ Physiological animal geography. Jour. Morph. (Whitman Volume), vol. 22, pp. 551-617.

Shelford, V. E. ANd Allee, W. C. 1912 An index of fish environments. Science, N. S.; vol. 36 , no. 916 .

Smith, Aurelia C. 1902 The influence of temperature, odors, light, and contact on the movements of earthworms. Am. Jour. Physiol., vol. 6, pp. 459-486.

Spauloring, E. G. 1904 An establishment of association in hermit crabs, Eupagurus longicarpus. Jour. Comp. Neur., vol. 19, pp. 49-61.

v. UnxrüLx, J. 1897 Über Reflexe bei Seeigeln. Zeitschr. f. Biol,, vol. 34, pp. 298-318.

1899 Die. Physiologie der Pedicellarien. Zeitschr. f. Biol., vol. 37, pp. 334-403.

1900 Die Physiologie der Seeigelstachels. Zeitschr. f. Biol., vol. 39, pp. 73-112.

YERKEs, R. M. 1902 Habit formation in the green crab, Carcinus granulatus. Biol. Bull., vol. 3, pp. 241-244.

Yenkes, R. M. ANd Hragres, G. E. 1903 Habit formation in the crawfish, Cambarus affinis. Harvard Psychol. Studies, no. 1, pp. 565-577. 